\title{
JAK-Inhibitors for the Treatment of Rheumatoid Arthritis: A Focus on the Present and an Outlook on the Future
}

\author{
Jacopo Angelini ${ }^{1,+}+\mathbb{C}$, Rossella Talotta ${ }^{2, *},+\left(\mathbb{C}\right.$, Rossana Roncato ${ }^{3} \mathbb{C}$, Giulia Fornasier ${ }^{1,4}$, \\ Giorgia Barbiero $^{1}$, Lisa Dal Cin ${ }^{1}$, Serena Brancati ${ }^{1}$ and Francesco Scaglione ${ }^{5}$ (D) \\ 1 Postgraduate School of Clinical Pharmacology and Toxicology, University of Milan, 20133 Milan, Italy; \\ jacopoangelini1@gmail.com (J.A.); giulia.fornasier@burlo.trieste.it (G.F.); \\ giorgia.barbiero.3@gmail.com (G.B.); lisa.dalcin@unimi.it (L.D.C.); serena.brancati@unimi.it (S.B.) \\ 2 Department of Clinical and Experimental Medicine, Rheumatology Unit, AOU "Gaetano Martino", \\ University of Messina, 98100 Messina, Italy \\ 3 Experimental and Clinical Pharmacology Unit, Centro di Riferimento Oncologico di Aviano (CRO), \\ Istituto di Ricovero e Cura a Carattere Scientifico (IRCCS), Pordenone, 33081 Aviano, Italy; \\ rossana.roncato@gmail.com \\ 4 Pharmacy Unit, IRCCS-Burlo Garofolo di Trieste, 34137 Trieste, Italy \\ 5 Head of Clinical Pharmacology and Toxicology Unit, Grande Ospedale Metropolitano Niguarda, \\ Department of Oncology and Onco-Hematology, Director of Postgraduate School of Clinical Pharmacology \\ and Toxicology, University of Milan, 20162 Milan, Italy; francesco.scaglione@unimi.it \\ * Correspondence: talotta1@virgilio.it; Tel.: +39-090-2111; Fax: +39-090-293-5162 \\ + Co-first authors.
}

Received: 16 May 2020; Accepted: 1 July 2020; Published: 5 July 2020

check for updates

\begin{abstract}
Janus kinase inhibitors (JAKi) belong to a new class of oral targeted disease-modifying drugs which have recently revolutionized the therapeutic panorama of rheumatoid arthritis (RA) and other immune-mediated diseases, placing alongside or even replacing conventional and biological drugs. JAKi are characterized by a novel mechanism of action, consisting of the intracellular interruption of the JAK-STAT pathway crucially involved in the immune response. The aim of this narrative review is to globally report the most relevant pharmacological features and clinical outcomes of the developed and incoming JAKi for RA, based on the available preclinical and clinical evidence. A total of 219 papers, including narrative and systematic reviews, randomized controlled trials (RCTs), observational studies, case reports, guidelines, and drug factsheets, were selected. The efficacy and safety profile of both the first generation JAKi (baricitinib and tofacitinib) and the second generation JAKi (upadacitinib, filgotinib, peficitinib, decernotinib and itacitinib) were compared and discussed. Results from RCTs and real-life data are encouraging and outline a rapid onset of the pharmacologic effects, which are maintained during the time. Their efficacy and safety profile are comparable or superior to those of biologic agents and JAKi proved to be efficacious when given as monotherapy. Finally, the manufacturing of JAKi is relatively easier and cheaper than that of biologics, thus increasing the number of compounds being formulated and tested for clinical use.
\end{abstract}

Keywords: Janus kinases; Janus kinase-inhibitors; rheumatoid arthritis; small molecules

\section{Introduction}

Rheumatoid arthritis (RA) is a chronic autoimmune disease affecting approximately $0.5-1 \%$ of the worldwide population. RA prevalence is higher in women aged between 35 and 50 years than in age-matched men, though this difference is less evident among elderly patients [1,2]. 
RA is characterized by a chronic synovitis that symmetrically develops in small joints of hands and feet, but any synovial joint can actually be involved [3]. Articular manifestations include swelling, tenderness, warmth, and decreased range of motion. Over time, persistent inflammation leads to the destruction of joints and tendons, and, eventually, to deformities and ankylosis. In some cases, RA can have an extra-articular presentation, and inflammation may involve the skin, heart, lungs, and eyes [4,5]. Generalized malaise and fatigue, pleural involvement, vasculitis, pericarditis, myocardial infarction, rheumatoid nodules, nerve entrapment syndromes, and keratoconjunctivitis sicca are the most common extra-articular manifestations [6].

The etiology of RA is multifactorial, and the initial cause is unknown. It is assumed that in a genetically predisposed individual, an environmental agent, like infections or dysbiosis, can trigger an aberrant immune response against self-antigens placed in the articular sites $[7,8]$. Genetic predisposition is mirrored by the high concordance rates in twins, and several cases have been shown to occur in the same family [9]. More than one hundred genetic loci have been associated with RA risk [10], most of which preside over the control of the immune response [11,12]. Among them, polymorphic variants of the human leukocyte antigen (HLA) genes, coding for molecules involved in the antigen presentation process, have been associated to a more aggressive course of the disease or higher mortality rates $[10,13]$.

Smoking, traumatic events, a low socioeconomic status, educational attainment, and periodontal disease are instead considered environmental risk factors for RA [14,15]. RA may be triggered by gut and oral dysbiosis or by infections sustained by Proteus mirabilis, Escherichia coli, or the Epstein-Barr virus [16,17]. Epigenetics may play an additional role in RA pathogenesis, being in turn influenced by environmental stimuli [18]. Histone deacetylation, DNA methylation, and microRNA production may affect the transcription of genes involved in inflammation, and are associated with disease risk and activity and response to treatment [19].

RA inflammation is due to the clonal expansion of autoreactive $\mathrm{T}$ cells, such as $\mathrm{T}$ helper (Th)17 lymphocytes and B lymphocytes at the detriment of T regulatory(reg) lymphocytes [20,21]. B lymphocytes mature to the final stage of plasma cells producing autoantibodies, including anti-citrullinated peptide antibodies (ACPAs) and rheumatoid factor (RF) that represent the serologic hallmark of the disease [21]. Autoreactive cells are recruited in the synovial membrane, where resident fibroblast-like and macrophage-like synoviocytes further contribute to the amplification of the inflammatory cascade through the release of several pro-inflammatory cytokines [7], like interleukin (IL)-1 and tumor necrosis factor-alpha (TNF- $\alpha$ ), IL-6, and IL-8 [22]. Additionally, Th17 lymphocytes secrete IL-17 that is crucially involved in bone resorption [20].

Persistent inflammation results in profound changes of the joint anatomy and physiology, progressing from synovial hyperplasia and endothelial cell activation in the early phase to cartilage destruction and bone erosion in the late phase [23].

The recent 2020 European League Against Rheumatism (EULAR) and the 2015 American College of Rheumatology (ACR) guidelines recommended to start treating RA patients as early as possible owing to the debilitating course of the disease, and subjects should be tightly monitored as therapy should be adjusted according to disease activity [24,25].

The treatment of RA relies on the use of drugs counteracting the aberrant activation of the immune system and includes anti-inflammatory and analgesic drugs, glucocorticoids, disease-modifying anti-rheumatic drugs (DMARDs), immunosuppressive agents, and biologics. The DMARD methotrexate (MTX), and to a lesser extent, leflunomide and sulfasalazine, have been considered as an anchor therapy in RA. Accordingly, their use, as mono- or combo-therapy, is recommended in the early phase of the disease, as well as to treat the milder forms of RA in the long term. Glucocorticoids and non-steroidal anti-inflammatory drugs (NSAIDs) are, instead, indicated for the acute management of RA flares, while the chronic use of these drugs is discouraged. Conventional (c)DMARDs, glucocorticoids, and NSAIDs are characterized by a low target specificity and may unselectively hamper physiological 
pathways other than the immune response, exposing patients to a not negligible risk of adverse events, like infections or gastrointestinal, cardiovascular, and hematologic disorders [26-28].

Since their advent in late 1990s [29], biological drugs consisting of monoclonal antibodies or fusion receptors targeting specific molecular or cellular pathways, notably improved the clinical course of RA, allowing the achievement of low disease activity or even remission in a high percentage of cases [30,31]. Additionally, in the last years, the formulation of oral compounds, known as small molecules, able to block some crucial steps of the inflammatory cascade, has further enriched RA therapeutic armamentarium. According to current therapeutic guidelines [24,25], biologic drugs and synthetic small molecules should be prescribed in the case of severe and refractory RA, but these medications may also be considered as the first therapy when poor prognostic factors are present [24].

Among synthetic small molecules, the Janus kinase inhibitors (JAKi) represent a new class of oral drugs counteracting the activation of JAKs, which are cytosolic enzymes presiding over many biologic functions, including the activation of the inflammatory cascade in immune cells [32]. Due to their central role in the immune response and their association with several cytokine receptors, the inhibition of JAKs appeared to be a promising strategy in autoimmune diseases. To date, some oral JAKi (tofacitinib, baricitinib, upadacitinib, peficitinib) have already been licensed for the treatment of RA and other immune-mediated diseases. Results from randomized controlled trials (RCTs) and real-life data are encouraging, and evidence a rapid onset of the pharmacologic effects, which are maintained over the course of time. Their efficacy and safety profile are comparable or superior to those of biologic agents, and JAKi proved to be efficacious when given as monotherapy [33]. In addition, the manufacturing of JAKi is relatively easier and cheaper than that of biologics, and thus noteworthy for increasing the number of compounds being formulated and tested for clinical use.

The panorama of JAKi designed for RA is extremely innovative and dynamic. The aim of this narrative review is therefore to comprehensively report and compare the pharmacological profile of JAKi approved for the treatment of RA, also providing evidence on JAKi currently under development. We discuss data concerning mechanistic, clinical, and pharmacoeconomic aspects, in order to support clinicians in the identification of the most appropriate place in therapy of these promising new drugs.

\section{Methods}

A literature research was conducted using PubMed, ClinicalTrials.gov, and Google Scholar databases, searching for the medical subject headings (MeSH) terms "rheumatoid arthritis", "JAK-inhibitors", "baricitinib", "tofacitinib", "upadacitinib", "peficitinib", "filgotinib", “decernotinib", and "itacitinib". A total of 219 papers, written in English and published between 1994 and 2020 and pertinent to the purpose of the review, were selected. They included narrative reviews (n. 74), RCTs (n. 70), systematic and evidence reviews and meta-analyses (n. 11), retrospective cohort studies (n. 16), observational case control studies (n. 31), cross-sectional and interventional studies (n. 1 and n. 2, respectively), case reports (n. 1), guidelines (n. 3), and drug factsheets and reports (n. 10) (Figure 1). Results are presented and discussed in the next sections. 


\begin{tabular}{|c|c|c|c|c|c|c|c|c|c|c|}
\hline \multirow[b]{2}{*}{ MeSH term } & \multirow[b]{2}{*}{$\begin{array}{c}\text { narrative } \\
\text { reviews }\end{array}$} & \multirow[b]{2}{*}{ RCTs } & \multicolumn{2}{|c|}{ PubMed } & \multirow{2}{*}{$\begin{array}{c}\text { ClinicalTrials.gov } \\
\downarrow \\
219 \text { papers } \\
(1994-2020) \\
\begin{array}{c}\text { observational } \\
\text { case control } \\
\text { studies }\end{array}\end{array}$} & \multicolumn{2}{|c|}{ Google Scholar } & \multirow[b]{2}{*}{$\begin{array}{l}\text { case } \\
\text { reports }\end{array}$} & \multirow[b]{2}{*}{ guidelines } & \multirow[b]{2}{*}{$\begin{array}{l}\text { drug } \\
\text { factsheets and } \\
\text { reports }\end{array}$} \\
\hline & & & $\begin{array}{c}\text { systematic and } \\
\text { evidence reviews } \\
\text { and meta-analyses }\end{array}$ & $\begin{array}{l}\text { retrospective } \\
\text { cohort } \\
\text { studies }\end{array}$ & & $\begin{array}{l}\text { cross-sectional } \\
\text { studies }\end{array}$ & $\begin{array}{l}\text { interventional } \\
\text { studies }\end{array}$ & & & \\
\hline $\begin{array}{c}\text { rheumatoid } \\
\text { arthritis }\end{array}$ & 31 & 1 & 1 & 4 & 1 & 1 & I & I & 3 & I \\
\hline JAKi & 35 & 1 & 4 & / & 21 & 1 & I & 1 & I & 1 \\
\hline baricitinib & 3 & 21 & 1 & 3 & 2 & I & 1 & I & I & 5 \\
\hline tofacitinib & 3 & 21 & 5 & 9 & 4 & I & 2 & 1 & I & 2 \\
\hline upadacitinib & 1 & 10 & 1 & 1 & 1 & I & 1 & I & I & 1 \\
\hline peficitinib & 1 & 7 & I & 1 & 1 & 1 & 1 & 1 & I & 1 \\
\hline filgotinib & 1 & 5 & I & 1 & 1 & 1 & I & I & 1 & I \\
\hline decernotinib & 1 & 3 & 1 & 1 & 1 & 1 & 1 & 1 & 1 & I \\
\hline itacitinib & & 3 & & & & & & & & 1 \\
\hline total & 74 & 70 & 11 & 16 & 31 & 1 & 2 & 1 & 3 & 10 \\
\hline
\end{tabular}

Figure 1. Literature selection process for this article (JAKi, JAK-inhibitors; RCTs, randomized controlled trials).

\section{General Pharmacological Properties of JAKi}

Cytokine signaling has been considered as an optimal pharmacological target for the treatment of RA and other autoimmune diseases. Both conventional and biological drugs approved for RA, in fact, act by preventing cytokine release and signaling.

JAKi block the specific adenosine triphosphate (ATP)-binding pocket, interrupting the JAK-Signal Transducer and Activator of Transcription (STAT) intracellular signaling cascade that ultimately leads to the activation of immune cells and their transition towards a pro-inflammatory phenotype [34]. Four different types of JAKs (JAK1, JAK2, JAK3, and tyrosine kinase 2, TYK2) and seven different STATs (STAT1, STAT2, STAT3, STAT4, STAT5A, STAT5B, STAT6) can variously combine and give raise to different biologic cascades [35], Table 1. JAKs are enzymes belonging to the family of tyrosine kinases constitutively bound to the intracellular domains of type I and II receptors. Type I receptors bind several ILs, colony stimulating factors, and hormones such as erythropoietin, prolactin, and growth hormone. Type II receptors bind interferons and IL-10 related cytokines [36].

In the canonical pathway, the interaction between cytokines and their cognate receptors induce their dimerization and the downstream activation of JAKs. Generally, cytokine receptors do not have intrinsic kinase activity, and use the binding of JAK enzymes for the autophosphorylation of tyrosine residues present in the cytoplasmic domains. This phosphorylation leads to the docking and the activation of the STAT proteins. JAKs phosphorylate STAT proteins with the consequent dimerization of STAT monomers and translocation into the nucleus. Here, STAT molecules behave as transcriptional factors, promoting the transcription of target genes [37], as shown in Figure 2. 
Table 1. Combinations of cytokines, types of JAK receptor-STAT proteins, cellular targets and possible related disorders.

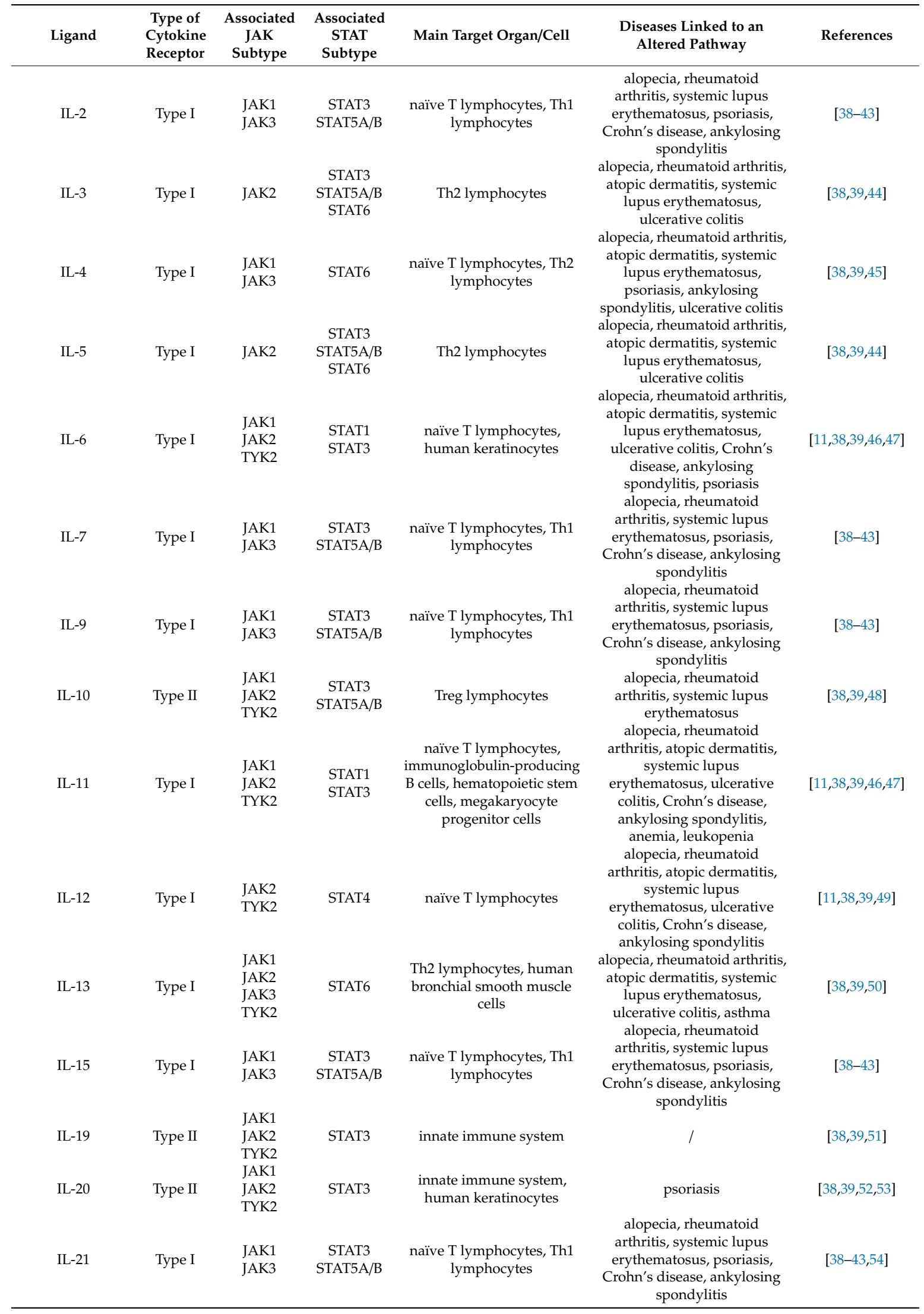


Table 1. Cont.

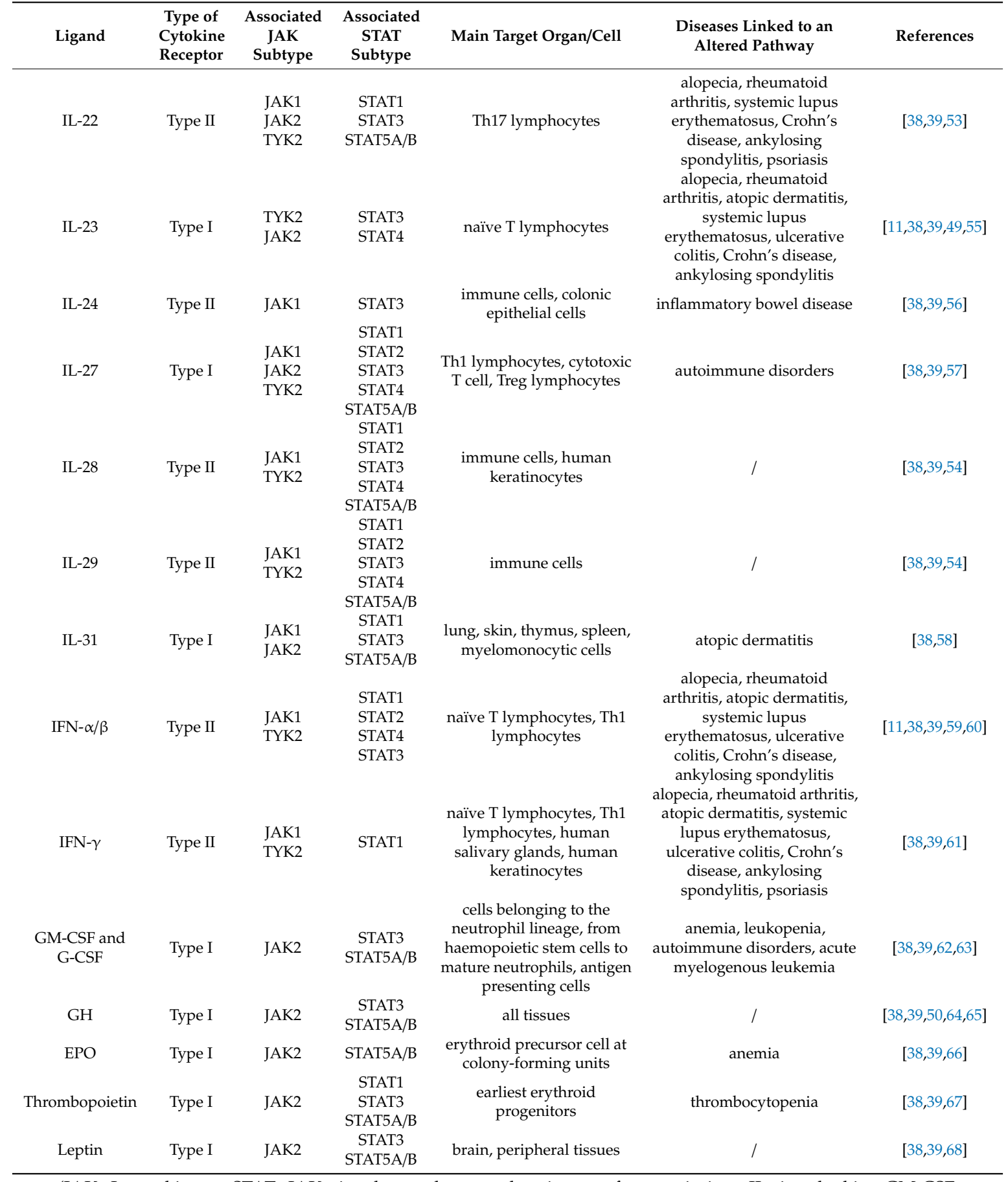

(JAK: Janus kinase; STAT: JAK signal transducer and activator of transcription; IL: interleukin; GM-CSF: granulocyte-macrophage colony-stimulating factor; TYK: tyrosine kinase; Th: T helper; GH: growth hormone; EPO: erythropoietin; G-CSF: granulocyte-colony stimulating factor; IFN: interferon; Treg, T regulatory). 


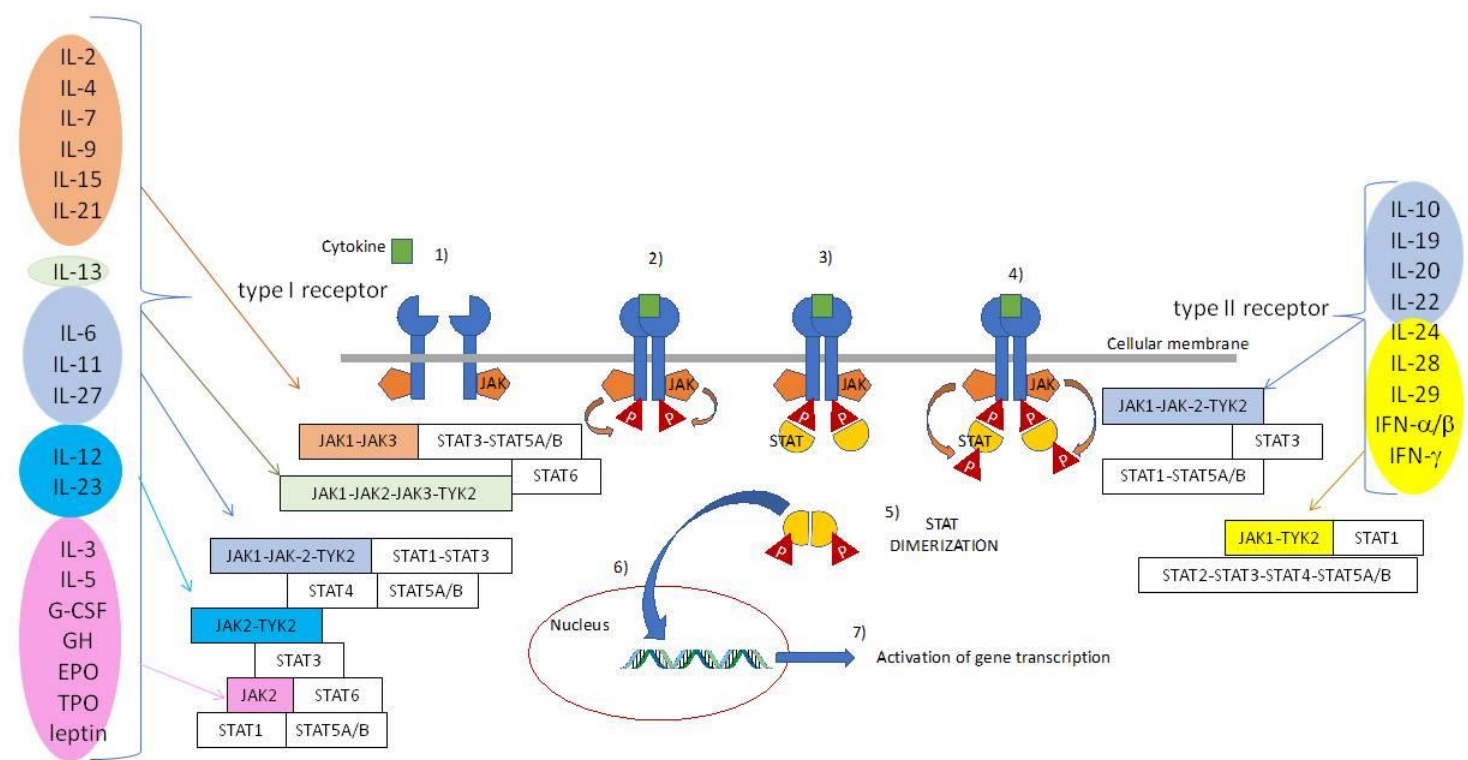

Figure 2. The JAK-STAT canonical signaling pathway. The specific cytokine binds to the transmembrane receptors type I o II. This binding causes the auto-phosphorylation of the receptor itself which summons cytosolic monomeric JAK proteins (1). Once recruited, JAKs phosphorylate the receptor (2), allowing, in turn, a second phosphorylation of STAT monomers $(3,4)$. STATs dimerize $(5)$ and translocate into the nucleus (6), activating the transcription of pro-inflammatory genes (7). (JAK: Janus kinase; STAT: JAK signal transducer and activator of transcription; IL: interleukin; G-CSF: granulocyte-colony-stimulating factor; TYK: tyrosine kinase; GH: growth hormone; EPO: erythropoietin; TPO: thrombopoietin; IFN: interferon).

Of note, JAK1 and JAK2 are found ubiquitously and modulate the expression of many inflammatory and non-inflammatory genes in response to IL-6, IL-23, granulocyte colony-stimulating factor, interferons, erythropoietin and other ligands [38-57,59-69]. JAK3 is, instead, expressed in hematopoietic cells and is involved in the signaling cascades unleashed by IL-2, IL-4, IL-7, IL-9, IL-15, and IL-21 [34,36].

The JAK-STAT pathway is highly conserved among species due to its involvement in many physiological processes, including the antimicrobial response, metabolism, cell proliferation and self-renew, and tissue regeneration [70]. The kinase activity is strictly regulated by phosphoprotein phosphatases and ubiquitin ligases that dephosphorylate JAKs or induce the proteasomal degradation of the JAK-receptor complex [71]. Accordingly, JAK and STAT loss-of-function and gain-of-function genetic variants have been associated with immunodeficiency and growth retardation and with cancer and autoimmunity, respectively [72].

Besides the canonical pathway, a non-canonical JAK-STAT signaling mechanism has additionally been described in animal models and human cells [73]. In Drosophila and mammalian cells, non-phosphorylated STAT forms may shuttle between cytosol and nucleus and affect the euchromatin/heterochromatin ratio without the engagement with STAT-activated genes [74]. Dimeric or multimeric STATs may form cytosolic molecular platforms recruiting chaperones or other proteins associated to organelles or involved in membrane trafficking [75]. Preclinical experiments showed that STAT3 may non-canonically preside over the integrity of microtubules and mitochondria and that STAT5A and STAT5B may control the normal functioning of the rough endoplasmic reticulum [76]. In nucleus, non-phosphorylated STAT1 and STAT3 molecules may couple with other transcriptional factors, like interferon regulatory factor-1 (IRF1) thus influencing the expression of additional genes [75]. Finally, JAK2 may epigenetically control gene transcription through histone phosphorylation [76].

It is worth underlining that the JAK-STAT pathway is not the only mechanism orchestrating the immune response in autoimmunity [77]. Other cytokines, like TNF- $\alpha$, trigger, in fact, distinct intracellular cascades, mostly converging on the activation of the transcriptional factors nuclear factor 
kappa-light-chain-enhancer of activated B cells (NF-kB) or nuclear factor of activated T-cells (NFAT), which eventually promote the expression of pro-inflammatory genes $[78,79]$. Notably, these signaling mechanisms may reciprocally influence one another: for instance, it has been shown that NF-kB may induce the expression of the suppressor of cytokine signaling (SOCS)3, in turn inactivating STAT3 in human glioblastoma cells [80], and that NFAT may engage with STAT3 in a dynamic ternary complex promoting the hypertrophy of cardiomyocytes in mouse models [81]. Furthermore, the evidence that JAK and STAT molecules may non-canonically modulate the cell transcriptome without requiring kinase activity should indeed deserve further investigation concerning a presumable residual activity during the pharmacologic inhibition of the JAK-STAT canonical pathway.

According to their selectivity, JAKi can be divided into first generation JAKi, consisting of non-selective inhibitors, and second generation JAKi, inhibiting the signaling of a narrower range of cytokines. The first generation JAKi encompasses baricitinib, which inhibits JAK1 and JAK2, and tofacitinib, which inhibits JAK1, JAK2, JAK3 and, to a lesser extent, TYK2 [82]; the second generation JAKi, includes, instead, upadacitinib, decernotinib, filgotinib, peficitinib and itacitinib, most of which are still under development. Second generation JAKi seem to have a faster and dose-dependent efficacy and appear more appealing when used as mono-therapy [83]. More selective JAKi should have a better safety profile; however, the complex interplay among cytokines and the ubiquity of the JAK-STAT molecules in cells not belonging to the immune system, though being helpful in the treatment of a broader range of diseases, may increases the risk of unwanted side effects.

Due to the repression of the immune response, infections, especially of the upper respiratory tract, are the most common side effect during the treatment with JAKi. In addition, reactivation of Herpes Zoster virus (HZV) and alteration in the blood lipid profile have typically been reported under JAKi therapy and appeared to be dose-dependent [84-86]. HZV reactivation seems to rely on the repression of the type I interferon response following JAK1 inhibition. Subsequently, vaccination against HZV is recommended before starting JAKi treatment $[87,88]$, especially in some genetically-predisposed ethnic groups and in patients concomitantly prescribed with MTX [89]. JAKi may induce high density lipoprotein (HDL) efflux from macrophages or prevent the IL-6-induced storage of blood lipids into peripheral tissues, and thus increase the level of low density lipoproteins (LDL), HDL and total cholesterol [90], without affecting the LDL/HDL cholesterol ratio. Nevertheless, the increase in blood cholesterol levels has not been correlated to an augmented risk of cardiovascular disease in clinical trials, confirming the theory, also known as "the lipid paradox phenomenon" [91], that in RA cardiovascular morbidity and mortality mostly depend on chronic inflammation rather than on other classical risk factors [92]. Likewise, all clinical studies on JAKi have shown a low incidence of cardiovascular events in treated cohorts of patients probably related to the anti-inflammatory role played by these small molecules [93].

Thanks to the interesting efficacy profile emerging from phase III and long-term extension trials [94], it is expected that the use of JAKi for the treatment of RA will notably increase in the next years. This may be further supported by a better therapeutic compliance and a more favorable pharmacoeconomic impact than those of biological agents and their biosimilars. The oral route of administration of JAKi has, in fact, the potential to minimize drug discontinuation in contrast to parentally administered biological products. Finally, the lower manufacturing costs of JAKi compared to those of biologics may result in a more positive pharmacoeconomic trend soon after the expiration of JAKi patent protection.

In order to provide a comprehensive overview of the panorama of JAKi in RA, the pharmacologic aspects of marketed JAKi and those under development for RA are singularly delineated and discussed in the following paragraphs. 


\section{Baricitinib}

\subsection{Chemical Structure, Pharmacokinetics, Pharmacodynamics and Mechanism of Action}

Baricitinib (International Union of Pure and Applied Chemistry (IUPAC) name: 2-[1-ethylsulfonyl-3-[4-(7H-pyrrolo[2,3-d]pyrimidin-4-yl)-1-pyrazolyl]-3-azetidinyl]acetonitrile) is a first generation JAKi, currently solely licensed for the treatment of moderate to severe active RA in adult patients who inadequately respond or are intolerant to one or more cDMARDs. Its chemical structure is that of a pyrrolopyrimidine, being insoluble in water and slightly soluble in hydrochloric acid $[95,96]$. Baricitinib was obtained by modifying the structure of tofacitinib, another first generation ATP-competitive JAKi. Both the drugs target the JH1 tyrosine kinase domain by interacting with the active conformational site of the ATP-binding pocket [97]. This structure is highly conserved among JAK enzymes, and, consequently, the first-generation JAKi unselectively target several JAKs. Baricitinib prevents the activation of both JAK1 and JAK2 molecules with half maximal inhibitory concentration (IC50) values of 5.9 and 5.7, respectively. This results in the inhibition of the expression of IL-6 in a dose-dependent manner [98]. When given to healthy subjects at a daily dose of $4 \mathrm{mg}$, the inhibition peaks after two hours since administration and lasts for $24 \mathrm{~h}$ [85]. Another relevant effect is the inhibition in vitro of osteoclastogenesis and thus subchondral bone erosions, through the down-regulation of receptor activator of nuclear factor- $\mathrm{B}$ ligand (RANKL) in osteoblasts [99].

In adult patients aged $<75$ years and without known risk factors, baricitinib is orally administered at a dosage of $2 \mathrm{mg}$ once daily. It can be used either in combination with MTX and other cDMARDs in patients partially responding to these medications or as monotherapy in those who discontinue conventional treatment due to intolerance or to the achievement of their treatment target [100]. Elderly subjects and those with a history of recurrent infections or renal function impairment should receive half-daily dose.

Baricitinib pharmacokinetic profiles after single or multiple administrations are comparable in healthy subjects [101]. After absorption, the bioavailability is $79 \%$ and, in blood, about $50 \%$ of the drug is bound to plasma proteins. In RA patients, the drug is rapidly absorbed with a time to peak (Tmax) of $1.5 \mathrm{~h}$, and a mean half-life of $12.5 \mathrm{~h}$ [102]. Meals decrease the intestinal absorption by $14 \%$ and maximum serum concentration (Cmax) by $18-29 \%$. The steady state is obtained within $48 \mathrm{~h}$ (or $6 \times$ half-life) after the first dose. The mean volume of distribution is $76 \mathrm{~L}$ after intravenous (i.v.) administration. Baricitinib is metabolized by hepatic enzymes, mainly belonging to the cytochrome P450 cluster (CYP3A4). Accordingly, the co-administration of baricitinib with CYP3A4 inhibitors or inducers should be carefully evaluated case by case. Nevertheless, studies of clinical pharmacology suggest that baricitinib does not require any dose adjustment in case of mild or moderate hepatic impairment, co-administration of proton pump inhibitors (PPI), CYP3A4 inhibitors (e.g., ketoconazole), moderate CYP3A/CYP2C19/CYP2C9 inhibitors (e.g., fluconazole) or strong CYP3A inducers (e.g., rifampicin) [85]. Furthermore, no meaningful interactions have been reported when other CYP3A drug substrates, such as MTX, simvastatin, ethinyl oestradiol, or levonorgestrel were co-administrated [103]. The drug is however contraindicated in patients with severe hepatic impairment [103].

Baricitinib is mostly eliminated by glomerular filtration and kidney tubule active transportation. This is mediated by organic anion transporter 3 (OAT3), glycoprotein-P, breast cancer resistance protein (BCRP), and multidrug and toxin extrusion protein $2 \mathrm{~K}$ (MATE-2K). Studies in RA patients with a preserved kidney function reported a renal clearance of baricitinib of $9.42 \mathrm{~L} / \mathrm{hour}$, which is slightly lower than that of healthy volunteers (12 L/hour) [101]. Patients with renal failure require a dose adjustment, and the drug is not recommended in patients having a creatinine clearance $<30 \mathrm{~mL} /$ minute $[101,104]$. Additionally, when baricitinib is co-administrated with digoxin, a substrate of glycoprotein-P, no meaningful alterations were detected [103]. 


\subsection{Efficacy}

The clinical efficacy of baricitinib as mono- or combo-therapy in patients with RA was assessed in a total of 4 randomized, double-blind, placebo-controlled phase III clinical trials: two long-term (52 weeks) active controlled trials (RA-BEGIN [105] and RA-BEAM Study [106]) and two shorter-term (24 weeks) 3-arm randomized placebo-controlled trials (RA-BUILD [107] and RA-BEACON [108]).

Patients who completed one of these main phase III clinical trials or a phase II exploratory trial [109] were eligible to entering the ongoing phase III single-blind multicenter long-term extension study RA-BEYOND $[110,111]$. These studies recruited RA patients naïve to conventional and biologic drugs (RA-BEGIN), those failing a precedent treatment with at least one cDMARD (RA-BEAM, RA-BUILD), or those failing a previous biologic therapy, including an anti-TNF agent (RA-BEACON). Studies differed in design and statistical analysis. Specifically, the RA-BEGIN trial tested the non-inferiority of baricitinib vs. MTX, while RA-BEAM, RA-BUILD and RA-BEACON were superiority trials vs. placebo. All the registration trials achieved the primary endpoint, consisting of the percentage of patients meeting the ACR20 improvement criteria (ACR20) at week 12 or 24. In addition, all major secondary endpoints, including ACR50 and ACR70 response rates, disease activity score on 28 joints by C-reactive protein (CRP) (DAS28-CRP) response, health assessment questionnaire disability index (HAQ-DI) response, simplified disease activity index (SDAI) remission rate and improvement from baseline in patient reported outcomes (PROs), were reached in the baricitinib arm compared to placebo. Of note, in the RA-BEAM trial [106], baricitinib was head to head compared with the anti-TNF monoclonal antibody adalimumab, resulting in a significant superiority to adalimumab in ACR20, ACR50 and ACR70 response rate until week 52, and in DAS28-CRP scores, SDAI remission achievement, HAQ-DI scores, and several PROs [112] at week 12.

In the RA-BUILD trial [107], a statistically significant reduction in the radiographic progression of structural joint damage from baseline to week 24 was observed for both $2 \mathrm{mg}$ and $4 \mathrm{mg}$ baricitinib groups compared with the placebo, though the effect was stronger with baricitinib $4 \mathrm{mg} /$ day. These results were confirmed in a two-year analysis in patients who completed RA-BEGIN, RA-BEAM, and RA-BUILD trials [111].

The design of RA-BEYOND $[110,111]$ included also a sub-study in which patients who received baricitinib $4 \mathrm{mg}$ once daily for at least 15 months in originating studies and who achieved sustained low disease activity or remission were re-randomized to continue receiving baricitinib $4 \mathrm{mg}$ once daily or stepping down to $2 \mathrm{mg}$ daily with or without cDMARDs. This step-down sub-study was designed in accordance with international therapeutic guidelines, which recommend a dose tapering (but not discontinuation) of DMARDs in patients who have achieved a sustained disease control $[25,113]$. After 48 weeks, most of the patients assigned to either a step-down strategy or standard regimen were still in low disease activity or remission [114]. These results, together with some safety trends, including adverse events and infection rates that would seem to favor a $2 \mathrm{mg}$ daily dose, suggest that a dose tapering strategy could be considered in those patients whose RA disease activity has been kept under control with an inductive standard regimen. However, compared with the $4 \mathrm{mg}$ group, the reduction to $2 \mathrm{mg}$ was associated with a modest but statistically significant increase in tender and swollen joint count, physician global assessment, DAS28-CRP, clinical disease activity index (CDAI), and SDAI scores.

A synthesis of the main characteristics of the reported clinical trials on baricitinib is provided in Table 2. 
Table 2. Baricitinib phase III trials in moderate to severe rheumatoid arthritis

\begin{tabular}{|c|c|c|c|c|c|}
\hline Study & $\begin{array}{l}\text { RA-BEGIN MTX-Naïve } \\
(n=588)\end{array}$ & $\begin{array}{l}\text { RA-BEAM MTX-IR } \\
(n=1308)\end{array}$ & $\begin{array}{l}\text { RA-BUILD cDMARD-IR } \\
(n=684)\end{array}$ & $\begin{array}{l}\text { RA-BEACON bDMARD-IR } \\
(n=527)\end{array}$ & $\begin{array}{l}\text { RA-BEYOND OLE Study } \\
(n=3073)\end{array}$ \\
\hline Inclusion criteria & $\begin{array}{ll}\text { - } & \text { RA } \\
\text { - } & \text { Patients who received no } \\
\text { prior cDMARD therapy (up } \\
\text { to } 3 \text { weekly MTX } \\
\text { doses permitted) }\end{array}$ & $\begin{array}{ll}\text { - } & \text { Active RA } \\
\text { - } & \text { Patients with inadequate } \\
\text { response to MTX, who received } \\
\text { therapy for } \geq 12 \text { weeks before trial } \\
\text { entry, including } \geq 8 \text { weeks at } \\
\text { stable doses }\end{array}$ & $\begin{array}{l}\text { Active RA and inadequate } \\
\text { response or intolerance to } \geq \\
1 \text { cDMARD } \\
\text { - Use of up to } 2 \text { concomitant } \\
\text { cDMARDs was permitted at } \\
\text { entry; these must have been } \\
\text { used for at least } 12 \text { preceding } \\
\text { weeks with stable doses for at } \\
\text { least } 8 \text { preceding weeks }\end{array}$ & 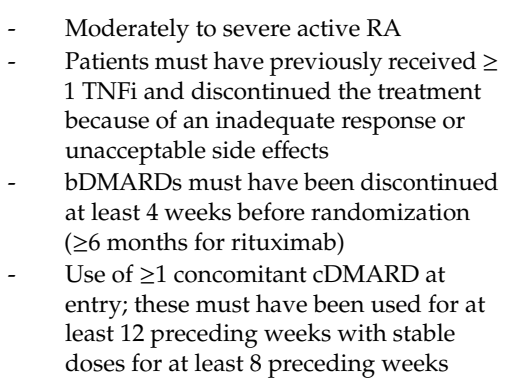 & $\begin{array}{l}\text { Patients who } \\
\text { completed a BARI } \\
\text { phase II or phase } \\
\text { III trial }\end{array}$ \\
\hline Type of therapy & $\begin{array}{l}\text { Monotherapy + combination } \\
\text { therapy }\end{array}$ & Combination therapy & Combination therapy & Combination therapy & $\begin{array}{c}\text { Monotherapy - patients } \\
\text { who completed previous } \\
\text { BARI RA studies }\end{array}$ \\
\hline $\begin{array}{l}\text { Background } \\
\text { treatment }\end{array}$ & None/MTX & MTX & cDMARDs & cDMARDs & cDMARDs \\
\hline $\begin{array}{l}\text { Active comparator } \\
\qquad \text { Arms }\end{array}$ & $\begin{array}{c}\text { MTX } \\
\text { (1) BARI 4 mg sid } \\
\text { (2) BARI 4 mg sid + MTX } \\
\text { (3) MTX } 10 \mathrm{mg} / \text { week }\end{array}$ & $\begin{array}{c}\text { ADA + MTX } \\
\text { (1) PBO } \\
\text { (2) BARI } 4 \mathrm{mg} \text { sid } \\
\text { (3) ADA } 40 \mathrm{mg} / \mathrm{sc} \mathrm{q} 2 \mathrm{wk}\end{array}$ & $\begin{array}{l}\text { (1) BARI } 2 \mathrm{mg} \text { sid } \\
\text { (2) BARI } 4 \mathrm{mg} \text { sid } \\
\text { (3) PBO }\end{array}$ & $\begin{array}{l}\text { (1) BARI } 2 \mathrm{mg} \text { sid } \\
\text { (2) BARI } 4 \mathrm{mg} \text { sid } \\
\text { (3) PBO }\end{array}$ & $\begin{array}{l}\text { (1) BARI } 2 \mathrm{mg} \text { sid } \\
\text { (2) BARI } 4 \mathrm{mg} \text { sid }\end{array}$ \\
\hline Duration (weeks) & 52 & 52 & 24 & 24 & $\begin{array}{l}\text { Ongoing (completion } \\
\text { estimated in 2024) }\end{array}$ \\
\hline Primary endpoint & $\begin{array}{c}\text { ACR20 } \\
\text { (Week 24) }\end{array}$ & $\begin{array}{c}\text { ACR20 } \\
\text { (Week 12) }\end{array}$ & $\begin{array}{c}\text { ACR20 } \\
\text { (Week 12) }\end{array}$ & $\begin{array}{c}\text { ACR20 } \\
\text { (Week 12) }\end{array}$ & Long term Safety \\
\hline $\begin{array}{l}\text { Key secondary } \\
\text { endpoint }\end{array}$ & $\begin{array}{c}\text { Week 24: } \\
\text { DAS28-CRP } \\
\text { HAQ-DI } \\
\text { mTSS } \\
\text { SDAI remission }\end{array}$ & $\begin{array}{c}\text { Week 12: } \\
\text { DAS28-CRP } \\
\text { HAQ-DI } \\
\text { mTSS (Week 24) } \\
\text { SDAI remission } \\
\text { Morning Joint stiffness }\end{array}$ & $\begin{array}{c}\text { Week 12: } \\
\text { DAS28-CRP } \\
\text { HAQ-DI } \\
\text { SDAI remission } \\
\text { Morning Joint stiffness }\end{array}$ & $\begin{array}{l}\text { Week 12: } \\
\text { DAS28-CRP } \\
\text { HAQ-DI } \\
\text { SDAI remission }\end{array}$ & Long term Efficacy \\
\hline $\begin{array}{l}\text { Main results } \\
\text { (ACR20): }\end{array}$ & $\begin{array}{c}\text { (Week } 24) \\
\text { BARI } 4 \text { mg vs. MTX: } 77 \% \text { vs. } 62 \% \\
(p \leq 0.01) ; \text { BARI } 4 \mathrm{mg} \text { vs. BARI } 4 \\
\text { mg + MTX: } 77 \% \text { vs. } 78 \% \\
\text { (Week } 52) \\
\text { BARI } 4 \text { mg vs. MTX: } 73 \% \text { vs. } 56 \% \\
(p \leq 0.05) ; \text { BARI } 4 \text { mg vs. BARI } 4 \\
\text { mg + MTX: } 73 \% \text { vs. } 73 \%\end{array}$ & $\begin{array}{r}\text { (Week } 12) \\
\text { BARI vs. PBO: } 70 \% \text { vs. } 40 \%(p<0.001) ; \\
\text { BARI vs. ADA: } 70 \% \text { vs. } 61 \%(p=0.014) \\
\text { (week } 24) \\
\text { BARI vs. PBO: } 74 \% \text { vs. } 37 \%(p<0.001) \\
\text { BARI vs. ADA: } 74 \% \text { vs. } 66 \%(p \leq 0.05)\end{array}$ & $\begin{array}{c}\text { (Week } 12) \\
\text { BARI } 2 \text { mg vs. PBO: } 66 \% \text { vs. } 39 \% \\
(p \leq 0.001) ; \text { BARI } 4 \mathrm{mg} \text { vs. PBO: } \\
62 \% \text { vs. } 39 \%(p \leq 0.001)\end{array}$ & $\begin{array}{c}\text { (Week } 12) \\
\text { BARI } 2 \text { mg vs. PBO: } 49 \% \text { vs. } 27 \%(p<0.001) \\
\text { BARI } 4 \text { mg vs. PBO: } 55 \% \text { vs. } 27 \%(p<0.001) \\
\text { (Week } 24) \\
\text { BARI } 2 \text { mg vs. PBO: } 45 \% \text { vs. } 27 \%(p \leq 0.001) ; \\
\text { BARI } 4 \text { mg vs. PBO: } 46 \% \text { vs. } 27 \%(p \leq 0.001)\end{array}$ & Currently recruiting \\
\hline
\end{tabular}




\subsection{Selected Populations}

\subsubsection{Pediatric Patients}

No published data are currently available concerning the use of baricitinib in the pediatric population affected by juvenile idiopathic arthritis (JIA), although three phase III clinical trials (ClinicalTrials.gov ID: NCT03773978, NCT03773965 and NCT04088396) are at present evaluating the efficacy and safety of baricitinib in patients aged from one or two years to less than 18 years and affected by polyarticular or systemic JIA. The achievement of the clinical endpoints in JIA is challenged by the disease's unpredictable expression and course. JIA encloses polyhedral manifestations, which may variously involve joints (poly- and pauci-articular forms) or extra-articular sites, or have a systemic development with distinct autoantibody patterns [115]. Around two thirds of pediatric patients affected by JIA may progress to other forms of arthritis in adulthood, which include RA but also seronegative arthritis. However, pathogenic pathways in JIA and adult RA are largely overlapping [115], and the use of oral JAKi could be of great interest in this subset of patients, whose compliance to parenterally administrated drugs, like biologics, is often limited.

\subsubsection{Selected Ethnic Groups}

Due to the differences between Asian and non-Asian populations in terms of genetic background [116], RA prevalence [117], demographic characteristics and clinical practice (patients with RA in Japan are often prescribed with lower doses of MTX compared with patients in the United States, US [118]), additional subgroup analyses of the four main phase III trials were performed in order to evaluate the efficacy and safety profile of baricitinib in 394 Japanese patients and to assess whether results in this ethnic cohort were consistent with those emerged in overall study population [119]. In all phase III RCTs, the safety and tolerability profile of baricitinib in Japanese patients appeared acceptable and generally consistent with results from the prior phase IIb study of baricitinib in Japan [120] and its long-term extension [121], and with the overall study population data. An increased tendency to develop HZV reactivation under baricitinib was however reported in this ethnic group [122].

\subsection{Safety}

The safety profile of baricitinib, emerging from the registration clinical trials and further analyses [105,120,123-128] on more than 3400 RA patients receiving a single dose of the drug, showed an incidence rate of serious adverse events (SAE) of eight in 100 patient-years of exposure (PYE) and a mortality rate of 0.33/100 PYE.

The majority of the reported adverse reactions were infections and hypercholesterolemia observed in $\geq 1 / 10$ cases. The most common infections (with a prevalence rate between 1/10 and 1/100) were pneumonia, HZV reactivation, gastroenteritis, urinary tract infections, and cellulitis. Hypercholesterolemia was a dose-dependent event. However, following an increase in the first 12 weeks of treatment, LDL and HDL serum levels were reported to stabilize [128]. No differences in terms of major cardiovascular events (MACE) were recorded between baricitinib and placebo in RCTs [129].

Generally, after 16 weeks of treatment, an increase in alanine transaminase (ALT) and aspartate transaminase (AST) was observed, especially when MTX was administered in combination $[77,85,104]$.

RCTs also evidenced an alteration in the blood count of platelets and hemoglobin blood value. In particular, platelet counts may increase in the first two weeks of therapy and then stabilize. Hemoglobin may initially decrease and then slowly increase [77,104].

Japanese patients were reported to have a higher risk of HZV infection compared to general population [122].

Evidence on long-term safety still relies on the completion of the ongoing long-term extension studies, as well as pharmacovigilance real-life data. The most common adverse drug reactions during baricitinib therapy reported by Medical Dictionary for Regulatory Activities (MedDRA) system organ 
class in Eudravigilance, Food and Drug Administration (FDA) adverse event reporting system (FAERS), and Vigiacess database, updated until 28 February 2020, are presented in Table 3.

Table 3. List of adverse reactions reported under treatment with baricitinib by MedDRA system organ class in Eudravigilance, FAERS and Vigiacess database.

\begin{tabular}{|c|c|c|c|}
\hline \multirow[b]{2}{*}{ Reaction Groups } & \multicolumn{3}{|c|}{$\begin{array}{c}\text { Number of Individual Cases by Reaction Groups } \\
\text { (Updated on } 28 \text { February 2020) }\end{array}$} \\
\hline & VigiAccess & Eudravigilance & FAERS \\
\hline Blood and lymphatic system disorders & $176(2.0 \%)$ & $98(3.5 \%)$ & $46(2.2 \%)$ \\
\hline Cardiac disorders & $117(1.3 \%)$ & $57(2.1 \%)$ & $54(2.6 \%)$ \\
\hline Congenital, familial and genetic disorders & $1(0.0 \%)$ & $1(0.0 \%)$ & $2(0.1 \%)$ \\
\hline Ear and labyrinth disorders & $41(0.5 \%)$ & $15(0.5 \%)$ & $11(0.5 \%)$ \\
\hline Endocrine disorders & $7(0.1 \%)$ & $1(0.0 \%)$ & $1(0.0 \%)$ \\
\hline Eye disorders & $110(1.3 \%)$ & $36(1.3 \%)$ & $32(1.6 \%)$ \\
\hline Gastrointestinal disorders & $879(10.0 \%)$ & $310(11.2 \%)$ & $181(8.8 \%)$ \\
\hline General disorders and administration site conditions & $1308(14.9 \%)$ & $326(11.8 \%)$ & $282(13.7 \%)$ \\
\hline Hepatobiliary disorders & $66(0.8 \%)$ & $42(1.5 \%)$ & $46(2.2 \%)$ \\
\hline Immune system disorders & $88(1.0 \%)$ & $15(0.5 \%)$ & $26(1.3 \%)$ \\
\hline Infections and infestations & $2095(23.9 \%)$ & $615(22.2 \%)$ & $371(18.0 \%)$ \\
\hline Injury, poisoning and procedural complications & $348(4.0 \%)$ & $77(2.8 \%)$ & $91(4.4 \%)$ \\
\hline Metabolism and nutrition disorders & $162(1.8 \%)$ & $75(2.7 \%)$ & $28(1.4 \%)$ \\
\hline Musculoskeletal and connective tissue disorders & $889(10 \%)$ & $151(5.4 \%)$ & $129(6.3 \%)$ \\
\hline $\begin{array}{l}\text { Neoplasms benign, malignant and unspecified (including cyst } \\
\text { and polyps) }\end{array}$ & $99(1.1 \%)$ & $70(2.5 \%)$ & $100(4.9 \%)$ \\
\hline Nervous system disorders & $566(6.5 \%)$ & $175(6.3 \%)$ & $158(7.7 \%)$ \\
\hline Pregnancy, puerperium and perinatal conditions & $4(0.0 \%)$ & $4(0.1 \%)$ & $1(0.0 \%)$ \\
\hline Product issues & $3(0.0 \%)$ & $0(0.0 \%)$ & $3(0.1 \%)$ \\
\hline Psychiatric disorders & $206(2.3 \%)$ & $56(2.0 \%)$ & $47(2.3 \%)$ \\
\hline Renal and urinary disorders & $134(1.5 \%)$ & $40(1.4 \%)$ & $37(1.8 \%)$ \\
\hline Reproductive system and breast disorders & $49(0.6 \%)$ & $16(0.6 \%)$ & $5(0.2 \%)$ \\
\hline Respiratory, thoracic and mediastinal disorders & $612(7 \%)$ & $247(8.9 \%)$ & $170(8.3 \%)$ \\
\hline Skin and subcutaneous tissue disorders & $504(5.7 \%)$ & $199(7.2 \%)$ & $89(4.3 \%)$ \\
\hline Surgical and medical procedures & $60(0.7 \%)$ & $1(0.0 \%)$ & $73(3.5 \%)$ \\
\hline Vascular disorders & $248(2.8 \%)$ & $147(5.3 \%)$ & $75(3.6 \%)$ \\
\hline Total & $8772(100 \%)$ & $2774(100 \%)$ & $2058(100 \%)$ \\
\hline
\end{tabular}

\subsection{Pharmacoeconomics}

According to two pharmacoeconomic studies, baricitinib has been considered a cost-effective treatment for RA patients with a previous inadequate response or intolerance to cDMARD therapy compared to adalimumab $[130,131]$. The same result was confirmed in the analysis including the hypothetical discount scenario of market entry of adalimumab biosimilar [130]. From a US budget analysis, baricitinib was considered an equally effective and less expensive option compared to other biologic (b)DMARDs in RA patients with an active disease and an inadequate response to previous anti-TNF agents [132].

Although international recommendations did not express a definite ranking, a single technology appraisal from the National Institute for Health and Care Excellence (NICE) estimated an incremental cost-effectiveness ratio (ICER) for baricitinib, in combination with MTX, vs. intensive cDMARDs being $£ 37,420$ per quality-adjusted life year gained (QALY). This value is included in the range usually considered by NICE as a cost-effective use of national health service resources. The use of baricitinib in combination with MTX was judged less cost-effective than RTX plus MTX by NICE. Consequently, it was recommended as an option for patients with severe RA who can tolerate MTX if: (1) they have cDMARD inadequate response; (2) they have an anti-TNF inadequate response and rituximab (RTX) in combination with MTX is not an option; or (3) they have an anti-TNF inadequate response and have already been treated with RTX. NICE also recommended baricitinib in monotherapy or in combination with MTX as a cost-effective use of National Health Service resources in patients with severe RA, except for patients with inadequate response to anti-TNF who are RTX-eligible. In the latter case, the ICER for 
etanercept biosimilars, certolizumab pegol and adalimumab, all in combination with MTX, were lower than $£ 30,000$ per QALY compared with baricitinib in combination with MTX [133].

\section{Tofacitinib}

\subsection{Chemical Structure, Pharmacokinetics, Pharmacodynamics and Mechanism of Action}

Tofacitinib (IUPAC name: 3-[(3R,4R)-4-methyl-3-[methyl(7H-pyrrolo[2,3-d]pyrimidin-4-yl)amino] piperidin-1-yl]-3-oxopropanenitrile) is a pyrrolopyrimidine, a $\mathrm{N}$-acylpiperidine, a nitrile and a tertiary amino compound. As citrate salt, it is soluble in dimethyl sulfoxide (DMSO) at a concentration of $100 \mathrm{mg} / \mathrm{mL}$, slightly soluble in water at a concentration of $2.9 \mathrm{mg} / \mathrm{mL}$ after warming, and very slightly soluble in $99.5 \%$ ethanol [134].

Tofacitinib is a non-selective first generation JAKi. The drug has three labeled indications: RA, psoriatic arthritis (PsA) and ulcerative colitis (UC), and acts by inhibiting JAK1, JAK2, JAK3 and, to a lesser extent, TYK2.

Tofacitinib is orally administered at a dosage of $5 \mathrm{mg}$ twice a day. After oral administration, it is rapidly absorbed with a Tmax of $0.5-1.0 \mathrm{~h}$, and has a half-life of $3.2 \mathrm{~h}$ [135]. The drug has a dose-proportional pharmacokinetics. The steady-state is obtained $24-48 \mathrm{~h}$ after the first dose. Food decreases $\mathrm{Cmax}$ by $32 \%$ without affecting the area under the curve (AUC).

The mean volume of distribution is $87 \mathrm{~L}$ after i.v. administration, with an equal distribution in red blood cells and plasma. About $40 \%$ of the drug is bound to plasma proteins.

Tofacitinib inhibition of STAT is reversible $24 \mathrm{~h}$ after the cessation of treatment, while it lasts for 2 weeks in patients who received the treatment for a minimum of 4 consecutive weeks [82]. In ex-vivo experiments, it has been shown that tofacitinib decreases the expression of the IL- 6 gene after a treatment period of 12 to 24 weeks, having instead a variable effect on that of IL-8, TNF- $\alpha$ and IL-10 genes [82]. In a study on RA patients, the serum levels of TNF- $\alpha$, IL-17, IL-6, and IFN- $\gamma$ significantly decreased following a four-week treatment with tofacitinib, whilst those of IL-35, mirroring Treg lymphocyte response, augmented [136]. Similar results were reported in responder psoriatic patients after 4 weeks of treatment [137]. In addition, in vitro studies exposing synovial membrane samples of PsA patients to the drug, further demonstrated an additional anti-angiogenic and anti-migrational effect $[138,139]$. Of note, tofacitinib suppresses in vitro the action of antigen presenting cells, by reducing the expression of the costimulatory molecules CD80/CD86 and by preventing the release of type I interferon [140]. Treatment with tofacitinib up to six months has been associated with a dose-dependent effect on white blood cells of RA individuals, including a reduction in natural killer (NK) cells (usually at 8-10 weeks of therapy and with a spontaneous reconstitution within 2-6 weeks after the discontinuation of treatment) and an increase in B cell count [141]. In healthy volunteers, no significant change in T-lymphocyte and their subsets has been reported in the short-medium term, whereas a prolonged treatment (approximately 5 years) has been associated with a reduction in $T$ cells and an increase in NK cells from baseline [142]. Of note, lymphocyte subsets normalize after the temporary discontinuation of treatment and have not been associated with serious or opportunistic infections or with HZV reactivation. Although influencing the count of B cells in RA patients, tofacitinib seems not to affect the production of antibodies in healthy individuals [142]. However, a study conducted on umbilical cord blood B cells and B lymphocytes of tofacitinib-treated patients evidenced that the drug may interfere with the maturation of B naive lymphocytes [143].

Tofacitinib is the only non-selective JAKi able to prevent the tolerogenic IL-27 pathway, in turn mediated by TYK2 signaling [144]. However, the drug is also able to hamper the STAT3-mediated differentiation of Th17 lymphocytes, thus counteracting the development of autoreactive cells [145].

As for baricitinib, tofacitinib has a hepatic metabolism through the cytochrome CYP3A4 [135], and, to a lesser extent, CYP2C19. Accordingly, also in this case, the co-administration of tofacitinib with CYP3A4 and CYP2C9 inhibitors or inducers should be carefully monitored. 
Contrary to baricitinib, the excretion of tofacitinib is mainly via the gastro-intestinal apparatus with only $30 \%$ of inactive metabolites excreted in urine. The renal and hepatic clearance are $124 \mathrm{~mL} / \mathrm{min}$ and $289 \mathrm{~mL} / \mathrm{min}$, respectively [134,135]. Therefore, the use of tofacitinib appears safer than that of baricitinib in patients with an impairment of the renal function. Tofacitinib can be also used in patients with a moderate hepatic failure, though a dose reduction is required [146].

\subsection{Efficacy}

The clinical efficacy of oral tofacitinib $5 \mathrm{mg}$ and $10 \mathrm{mg}$ twice daily as monotherapy or in combination with cDMARDs for the treatment of RA has been reported in six pivotal randomized, double-blind, multicentric phase III clinical studies (ORAL Solo-A3921045 [147]; ORAL Start-A3921069 [148]; ORAL Sync-A3921046 [149]; ORAL Scan-A3921044 [150]; ORAL Standard-A3921064 [151]; ORAL Step-A3921032 [152]), and in two open-label long-term extension studies (ORAL Sequel Study-A3921024 [87] and the Japanese study A3921041 [153]). Two studies (ORAL Scan and ORAL Start) assessed radiographic outcomes $[148,150]$. Recruited patients included MTX-naïve subjects (ORAL Start trial), inadequate responders to MTX or other cDMARDs (ORAL Scan, ORAL Sync and Oral Standard) and inadequate responders to biologics (ORAL Step, ORAL Sync and ORAL Solo).

Globally, the studies confirmed the clinical and radiographic efficacy of tofacitinib at both the doses of 5 and $10 \mathrm{mg}$ twice daily. In the ORAL Start trial [148], the coprimary efficacy endpoints, consisting of the mean change from baseline of the modified total Sharp score (mTSS) and the ACR70 response rate at month 6, were met: of note, the mean change in the mTSS from baseline was significantly smaller in the tofacitinib groups than in the MTX group, although changes were modest in all the three groups. Significant clinical and radiographic improvements were reported as early as month 1 and sustained over 24 months.

Similarly, in the ORAL Solo, ORAL Step, ORAL Standard, and ORAL Scan trials, benefits concerning DAS28-erythrocyte sedimentation rate (ESR) scores, ACR20-ACR50-ACR70 response rates, HAQ-DI and PROs scores were already reported at month 3 [147,150-152].

The ORAL Standard trial, conducted on RA patients who were MTX-non responder, compared tofacitinib to adalimumab [151]. Although a formal non-inferiority comparison among the active treatments was not made, the clinical efficacy of tofacitinib resulted numerically similar to that observed with adalimumab, with clinical responses achieved in both the two treatment arms by 1 month and sustained to month 12 . These results are in contrast to what was reported with baricitinib in the RA-BEAM trial, in which baricitinib showed superiority over adalimumab in the ACR20 response rate and mean change in DAS28-CRP at week 12 [119]. Although studies differed in the design, the apparent higher efficacy of baricitinib could be reconducted to its mechanism of action. Being more selective on JAK1 than tofacitinib, baricitinib strongly prevents the secretion of IL-6, and the following IL-6 blockade may play a more powerful therapeutic effect than the inhibition of TNF- $\alpha$ [154]. Anyway, to date, no published data on the direct comparison between baricitinib and tofacitinib are available, although a trial (ClinicalTrials.gov ID NCT03755466) is ongoing.

The phase 3b/4 ORAL Strategy trial [155], conducted in RA patients with active disease despite a previous treatment with MTX, showed comparable results in terms of ACR responses, DAS28-ESR remission and low disease activity rates at month 6 between the tofacitinib ( $5 \mathrm{mg}$ twice a day) and the adalimumab arm. Of note, in this study, tofacitinib monotherapy showed less efficacy than in combination with MTX.

Physical function (HAQ-DI score and other PROs) improved from baseline to a generally similar extent in patients receiving tofacitinib plus MTX, adalimumab plus MTX or tofacitinib monotherapy [156].

The long-term effect of tofacitinib has been explored in the ORAL Sequel study, including 4481 patients who had previously completed a phase I, II, or III study of tofacitinib and received open-label tofacitinib $5 \mathrm{mg}$ or $10 \mathrm{mg}$ twice a day [87]. Statistical analysis demonstrated that both clinical and functional index scores were maintained over the time between months 1 and 96 and were 
generally similar with tofacitinib $5 \mathrm{mg}$ and $10 \mathrm{mg}$ twice a day. Also, CDAI- and SDAI-defined remission were still reported in approximately one third of patients at month 96 , with a limited structural damage progression during longer-term therapy [157].

A synthesis of the main characteristics of clinical trials on tofacitinib is reported in Table 4.

Table 4. Tofacitinib phase III clinical trials in moderate to severe rheumatoid arthritis.

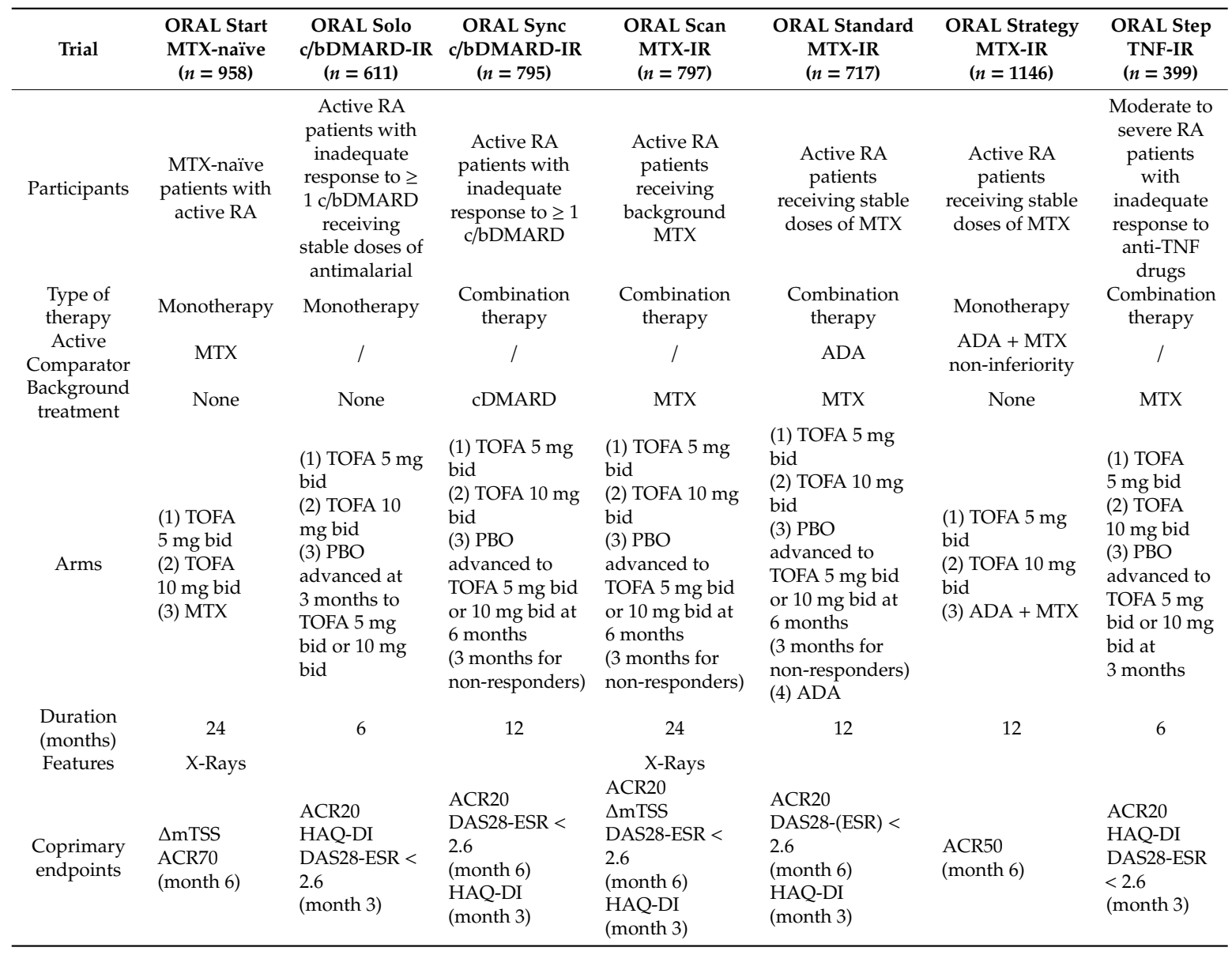


Table 4. Cont

\begin{tabular}{|c|c|c|c|c|c|c|c|}
\hline Trial & $\begin{array}{l}\text { ORAL Start } \\
\text { MTX-naïve } \\
(n=958)\end{array}$ & $\begin{array}{l}\text { ORAL Solo } \\
\text { c/bDMARD-IR } \\
\quad(n=611)\end{array}$ & $\begin{array}{c}\text { ORAL Sync } \\
\text { c/bDMARD-IR } \\
(n=795)\end{array}$ & $\begin{array}{c}\text { ORAL Scan } \\
\text { MTX-IR }(n= \\
\text { 797) }\end{array}$ & $\begin{array}{c}\text { ORAL Standard } \\
\text { MTX-IR }(n= \\
\text { 717) }\end{array}$ & $\begin{array}{c}\text { ORAL Strategy } \\
\text { MTX-IR }(n= \\
\text { 1146) }\end{array}$ & $\begin{array}{l}\text { ORAL Step } \\
\text { TNF-IR }(n= \\
\text { 399) }\end{array}$ \\
\hline Main results & $\begin{array}{l}\text { (Month 6) } \\
\text { ACR20 (\% } \\
\text { pts): } 71.3 \\
(p<0.001) \\
\text { TOFA } 5 \mathrm{mg} ; \\
76.1 \text { ( } p \leq 0.01) \\
\text { TOFA } 10 \mathrm{mg} ; \\
50.5 \text { MTX. } \\
\text { ACR70 (\% } \\
\text { pts): } 25.5 \\
(p<0.001) \\
\text { TOFA } 5 \mathrm{mg} ; \\
37.7(p \leq 0.01) \\
\text { TOFA } 10 \mathrm{mg} ; \\
12 \text { MTX. } \\
\text { HAQ-DI } \\
\text { (change from } \\
\text { BL): }-0.8 \\
(p<0.001) \\
\text { TOFA } 5 \mathrm{mg} ; \\
-0.9 \\
(p<0.001) \\
\text { TOFA } 10 \mathrm{mg} ; \\
-0.6 \text { MTX. } \\
\text { DAS28-ESR }< \\
2.6 \text { (\% pts): } \\
14.6(p \leq 0.05) \\
\text { TOFA } 5 \mathrm{mg} ; \\
21.8(p \leq 0.01) \\
\text { TOFA } 10 \mathrm{mg} ; \\
7.6 \text { MTX. } \\
\Delta \mathrm{mTSS}(\text { from } \\
\text { baseline): } 0.2 \\
(p<0.001) \\
\text { TOFA } 5 \mathrm{mg} ; \\
<0.1 \\
(p<0.001) \\
\text { TOFA } 10 \mathrm{mg} ; \\
0.8 \text { MTX }\end{array}$ & $\begin{array}{l}\text { (Month } 3) \\
\text { ACR20 (\% pts): } \\
59.8(p<0.001) \\
\text { TOFA } 5 \mathrm{mg} ; \\
65.7(p<0.001) \\
\text { TOFA } 10 \mathrm{mg} ; \\
26.7 \text { PBO. } \\
\text { HAQ-DI } \\
\text { (change from } \\
\text { BL): -0.5 } \\
(p<0.001) \\
\text { TOFA } 5 \mathrm{mg} ; \\
-0.57 \\
(p<0.001) \\
\text { TOFA } 10 \mathrm{mg} ; \\
-0.19 \text { PBO. } \\
\text { DAS28-ESR < } \\
2.6 \\
\text { (\% pts): } 5.6 \\
\text { TOFA } 5 \mathrm{mg} ; \\
8.7 \text { TOFA } \\
10 \text { mg; } 4.4 \text { PBO }\end{array}$ & $\begin{array}{l}\text { (Month 6) } \\
\text { ACR20 (\%pts): } \\
52.7(p<0.001) \\
\text { TOFA } 5 \mathrm{mg}+ \\
\text { cDMARD; } 56.6 \\
\text { ( } p<0.001) \\
\text { TOFA } 10 \mathrm{mg}+ \\
\text { cDMARD; } 31.2 \\
\text { PBO + } \\
\text { cDMARD. } \\
\text { HAQ-DI } \\
\text { (change from } \\
\text { BL): -0.44 } \\
\text { ( } p<0.001) \\
\text { TOFA 5 mg + } \\
\text { cDMARD; } \\
-0.53 \\
\text { ( } p<0.001) \\
\text { TOFA 10 mg+ } \\
\text { cDMARD; } \\
-0.21 \text { PBO + } \\
\text { cDMARD. } \\
\text { DAS28-ESR }< \\
2.6 \text { (\% pts): } 8.5 \\
(p \leq 0.01) \text { TOFA } \\
5 \text { mg + } \\
\text { cDMARD; } 12.5 \\
\text { ( } p<0.001) \\
\text { TOFA 10 mg + } \\
\text { cDMARD; } 2.7 \\
\text { PBO + } \\
\text { cDMARD }\end{array}$ & $\begin{array}{l}\text { (Month 6) } \\
\text { ACR20 (\%pts): } \\
51.5(p<0.001) \\
\text { TOFA } 5 \mathrm{mg}+ \\
\text { MTX; } \\
61.8(p<0.001) \\
\text { TOFA } 10 \mathrm{mg}+ \\
\text { MTX; } 25.3 \text { PBO } \\
\text { + MTX. } \\
\text { DAS28-ESR }< \\
\text { 2.6 (\% pts): 7.2 } \\
\text { TOFA } 5 \text { mg + } \\
\text { MTX; } 16.0 \\
\text { ( } p<0.001) \\
\text { TOFA } 10 \text { mg + } \\
\text { MTX; } \\
\text { 1.6 PBO + MTX. } \\
\text { HAQ-DI } \\
\text { (change from } \\
\text { BL): } \\
\text {-0.40 TOFA } \\
5 \text { mg + MTX; } \\
\text {-0.54 ( } p<0.001) \\
\text { TOFA 10 mg + } \\
\text { MTX; } \\
\text {-0.15 PBO + } \\
\text { MTX. } \\
\Delta \text { mTSS (from } \\
\text { baseline): } 0.12 \\
\text { TOFA } 5 \text { mg + } \\
\text { MTX; 0.06 } \\
\text { ( } p \leq 0.05) \text { TOFA } \\
10 \text { mg + MTX; } \\
0.47 \text { PBO + MTX }\end{array}$ & $\begin{array}{l}\text { (Month 6) } \\
\text { ACR20 (\%pts): } \\
51.5(p<0.001) \\
\text { TOFA } 5 \mathrm{mg}+ \\
\text { MTX; 52.6 } \\
(p<0.001) \text { TOFA } \\
10 \mathrm{mg}+\text { MTX; } \\
47.2(p<0.001) \\
\text { ADA + MTX; } \\
\text { 28.3 PBO+ MTX. } \\
\text { HAQ-DI (change } \\
\text { from BL): } \\
-0.55(p<0.001) \\
\text { TOFA } 5 \text { mg+ } \\
\text { MTX; }-0.61 \\
(p<0.001) \text { TOFA } \\
10 \text { mg + MTX; } \\
-0.49(p<0.001) \\
\text { ADA + MTX; } \\
-0.24 \text { PBO + } \\
\text { MTX. } \\
\text { DAS28-ESR }<2.6 \\
\text { (\% pts): } 7 \\
(p \leq 0.05) \text { TOFA } 5 \\
\text { mg + MTX; } 12.5 \\
(p<0.001) \text { TOFA } \\
10 \text { mg + MTX; } 6.7 \\
(p \leq 0.05) \text { ADA + } \\
\text { MTX; } 1.1 \text { PBO + } \\
\text { MTX }\end{array}$ & $\begin{array}{l}\text { (Month 6) } \\
\text { ACR20 (\% pts): } \\
65 \text { TOFA } 5 \mathrm{mg} ; \\
73.1 \text { TOFA } 5 \mathrm{mg} \\
\text { + MTX; } 71 \\
\text { ADA+ MTX. } \\
\text { ACR50 (\% pts): } \\
38.3 \text { TOFA } 5 \mathrm{mg} ; \\
46 \text { TOFA } 5 \mathrm{mg}+ \\
\text { MTX; } 44 \text { ADA+ } \\
\text { MTX. } \\
\text { HAQ-DI } \\
\text { (change from } \\
\text { BL): -0.54 TOFA } \\
5 \text { mg; -0.59 } \\
\text { TOFA } 5 \text { mg + } \\
\text { MTX; -0.54 } \\
\text { ADA + MTX. } \\
\text { DAS28-ESR < } \\
\text { 2.6 (\% pts): } 10.4 \\
\text { TOFA } 5 \text { mg; } 12 \\
\text { TOFA } 5 \text { mg + } \\
\text { MTX; } 12.4 \text { ADA } \\
\text { + MTX. }\end{array}$ & $\begin{array}{l}\text { (Month 3) } \\
\text { ACR20 }(\% \\
\text { pts): } 41.7 \\
(p \leq 0.01)) \\
\text { TOFA } 5 \mathrm{mg} \\
\text { + MTX; } 48.1 \\
(p<0.001) \\
\text { TOFA 10 mg } \\
\text { + MTX; } 24.4 \\
\text { PBO. + MTX } \\
\text { HAQ-DI } \\
\text { (change } \\
\text { from BL): } \\
-0.43 \\
(p<0.001) \\
\text { TOFA 5 mg + } \\
\text { MTX; -0.46 } \\
\text { ( } p<0.001) \\
\text { TOFA 10 mg } \\
+ \text { MTX; } \\
-0.18 \text { PBO + } \\
\text { MTX. } \\
\text { DAS28-ESR } \\
<2.6 \\
\text { ( } \% \text { pts): } 6.7 \\
(p \leq 0.05) \\
\text { TOFA } 5 \mathrm{mg} \\
+ \text { MTX; } 8.8 \\
(p \leq 0.05) \\
\text { TOFA 10 mg } \\
+ \text { MTX; } 1.7 \\
\text { PBO + MTX }\end{array}$ \\
\hline
\end{tabular}

The table summarizes the design and outcomes of tofacitinib phase III confirmatory studies for rheumatoid arthritis patients (RA, rheumatoid arthritis; ACR: American College of Rheumatology; ACR20: improvement by $20 \%$ from baseline of core set parameters; ADA: adalimumab; CDMARD: conventional disease-modifying anti-rheumatic drug; HAQ-DI: health assessment questionnaire-dDisability index; MTX: methotrexate; OLE: open label extension; mTSS: modified total Sharp score; PBO: placebo; SDAI: Simplified Disease Activity Index; TOFA: tofacitinib; DAS28-ESR: disease activity score on 28 joints by erythrocyte sedimentation rate; BL: baseline; bid: twice a day).

\subsection{Selected Populations}

\subsubsection{Pediatric Patients}

Evidence on the use of tofacitinib in pediatric population is limited. Few preliminary studies have been performed to establish the safety and pharmacokinetics of tofacitinib in patients affected by JIA [158]. The profile of efficacy and safety of tofacitinib 1-5 mg twice a day has been investigated in a recently completed phase III, randomized withdrawal, double-blind, placebo-controlled study in JIA patients ( 2 to <18 years) (A3921104; ClinicalTrials.gov ID NCT02592434; data not published). A phase II-III, long-term, open-label, follow-up study is also ongoing for those JIA patients who have previously participated in qualifying/index JIA studies of tofacitinib, including phase I studies (A3921165; Clinicaltrials.gov: NCT01500551), while a phase III, randomized, withdrawal, double blind, placebo-controlled study is currently recruiting patients with systemic JIA (A3921165; ClinicalTrials.gov ID NCT03000439).

Recently, Huang et al. [159] reported the case of a 13-year-old girl with recalcitrant systemic JIA non responder to glucocorticoids, cDMARDs and etanercept, who was prescribed with tofacitinib $2.5 \mathrm{mg}$ twice daily. The authors observed a stable improvement of both articular and systemic symptoms after 
2 months of treatment, with the achievement of a complete remission at month 3. Interestingly, no disease relapse or safety concerns occurred throughout the six months of follow-up.

\subsubsection{Selected Ethnic Groups}

The efficacy and safety profile of tofacitinib has been investigated in the long-term extension study A3921041 (ClinicalTrial.gov ID: NCT00661661), conducted in 486 Japanese patients who had participated to prior phase II or phase III studies of tofacitinib as monotherapy or in combination with MTX. Final results demonstrated a sustained efficacy profile of tofacitinib (with or without MTX), consistent with that observed in the main phase III studies, along with a stable safety profile, although a higher risk of HZV reactivation has been highlighted in Japanese patients compared to the general population [153].

\subsection{Indirect Studies Comparing Tofacitinib Efficacy}

As no robust evidence is available concerning direct comparisons between biologics in RA clinical trials, indirect comparisons (network meta-analysis and registries) could provide the most relevant and comprehensive data for a relative efficacy assessment.

One systematic review and network meta-analysis assessed the safety and effectiveness of biologics (abatacept, adalimumab, anakinra, certolizumab pegol, etanercept, golimumab, infliximab, rituximab and tocilizumab) and tofacitinib in RA patients who had an inadequate response to cDMARD treatment [160]. Data, collected from 79 trials and including 32,874 participants, failed to show a superiority of mono- or combo-therapy with tofacitinib in terms of improvement in the ACR50 response compared to biologic agents. Similarly, in patients taking cDMARDs, there was no significant difference between the likelihood of having better HAQ-DI scores following the administration of biologics or tofacitinib.

Another systematic review and network meta-analysis, assessing the safety and efficacy of tofacitinib in biologic-resistant patients, included data from 12 trials extrapolated on a cohort of 3364 participants [161]. Data analysis showed that for every 100 patients treated with tofacitinib plus MTX instead than with MTX alone, 19 additional patients would experience significant improvement in their RA symptoms (based on ACR50 response) compared to 16 patients treated with a biological agent plus MTX. Similarly, it was estimated that for every 100 patients treated with tofacitinib plus MTX instead than MTX alone, 6 extra patients would achieve DAS44 or DAS28 remission compared to 10 extra patients treated with a biologic drug plus MTX.

A network meta-analysis by Vieira et al., analyzing 5 trials for a total of 2136 patients, revealed that tofacitinib at a dose of $5 \mathrm{mg}$ twice a day combined with MTX was similar to biologics (abatacept, golimumab, rituximab, and tocilizumab) combined with cDMARDs in terms of the relative risk (RR) of ACR20, ACR50, and ACR70 responses and change from baseline in HAQ-DI scores [162].

These findings were confirmed by another network meta-analysis, which aimed to assess the efficacy of tofacitinib at a dose of 5 and $10 \mathrm{mg}$ twice a day given either as monotherapy or combined with MTX or other cDMARDs, in comparison with biologic and synthetic therapies (abatacept, adalimumab, anakinra, certolizumab pegol, etanercept, golimumab, infliximab, tocilizumab, and baricitinib) at 24 weeks [163]. Tofacitinib, given twice a day at a dose of $5 \mathrm{mg}$, showed comparable results to those observed with the use of other biologic monotherapies (tocilizumab, certolizumab, etanercept and adalimumab) in terms of ACR20 and ACR70 response rate at week 24. In addition, the combo-therapy of tofacitinib 5 and $10 \mathrm{mg}$ twice a day with MTX or other cDMARDs was more effective than certolizumab $400 \mathrm{mg}$ every 4 weeks plus MTX or other cDMARDs in the achievement of the ACR70 response. Tofacitinib $10 \mathrm{mg}$ twice a day revealed higher efficacy in the ACR20 response rate than etanercept, abatacept, and infliximab (all combined with cDMARDs). At 24 weeks, the ACR50 response rate indicated significantly higher efficacy of tofacitinib 5 and $10 \mathrm{mg}$ twice a day compared to baricitinib (all administered with concomitant therapies). Also, a higher percentage of patients under tofacitinib 
reached the ACR70 response at 24 weeks compared to adalimumab, abatacept, etanercept, infliximab and baricitinib $2 \mathrm{mg}$ daily plus cDMARDs.

Recently, results from the Swiss RA registry on a cohort of 2600 patients, of whom 806 treated with tofacitinib, were published [164]. The drug retention rate of tofacitinib was higher than that of anti-TNF agents but comparable with that of non-anti-TNF biologics (abatacept or anti-IL-6 agents). The use of cDMARDs improved the effectiveness of anti-TNF drugs, but not that of tofacitinib or non-anti-TNF biologics, supporting the efficacy of these drugs in monotherapy. Another recent study extrapolated real-life data from the Corrona US registry in order to evaluate the effectiveness of tofacitinib vs. anti-TNF drugs in RA patients [165]. A total of 558 subjects treated with tofacitinib from 2012 to 2016 were included. Interestingly, tofacitinib, either as mono- or combo-therapy, proved to be still effective even in patients with long-standing RA and receiving the drug as third or fourth option.

\subsection{Safety}

A safety report from phase II and III RTCs of tofacitinib showed that the majority of adverse events had a mild to moderate severity [147-152,166]. The most common side effects were nasopharyngitis (prevalence $\geq 1 / 10$ ), lower respiratory tract infections, HZV reactivation, urinary tract infections, nausea, increase in creatinine serum levels and liver enzymes, dyslipidemia with a modest and reversible increase of LDL and HDL levels [167], neutropenia, anemia, oedema, headache, and dyspnea (prevalence between $1 / 10$ and $1 / 100$ ) [134].

The decrease in neutrophil count has been considered to be dose-dependent [168], and, when it occurs in a moderate manner, it may be associated with a better clinical response in RA [82]. Generally, neutrophil count is stabilized after three months since the start of a treatment with tofacitinib. Hemoglobin value has been reported to initially decrease and then to slowly increase during the treatment $[87,169]$.

As for baricitinib, the concomitant administration of MTX may increase the risk of hyper-transaminasemia, and Japanese and Korean patients were reported to have a higher incidence of HZV infection than other populations [153].

Among SAE, the most common (prevalence between 1/10 and 1/100) were infections and malignancies (lympho-proliferative disorders and non-melanoma skin cancers) [170,171]. An integrated analysis of pooled safety data obtained from phase II and III RCTs on 5671 treated patients reported 107 malignancies developing under tofacitinib treatment [172]. Malignancies mainly affected the lungs, breast, or lymphoid organs, however they were stable over time and demonstrated an incidence in line with that reported in RA patients with a moderate to severe disease activity.

Of note, in May 2019 the European Medicines Agency (EMA)'s Safety Committee (PRAC) put a warning on the use of tofacitinib $10 \mathrm{mg}$ twice a day in individuals at high risk of lung thromboembolic events. These include patients suffering from heart failure, cancer, inherited blood clotting disorders or a history of blood clots, or subjects taking combined hormonal contraceptives, hormone replacement therapy or who undergo major surgery. This warning derived from the ongoing phase IV study A3921133 (ClinicalTrials.gov ID: NCT02092467), preliminarily reporting an increased risk of pulmonary embolism and death in RA patients assuming tofacitinib $10 \mathrm{mg}$ twice a day. Although this dosage is currently not recommended in RA patients in clinical practice, patients at risk of thrombotic events should be carefully monitored [173].

The most common adverse drug reactions reported by MedDRA system organ class in Eudravigilance, FAERS, and VigiAccess database are reported in Table 5. 
Table 5. List of adverse reactions reported under treatment with tofacitinib by MedDRA system organ class in Eudravigilance, FAERS and Vigiacess database.

\begin{tabular}{ccc}
\hline & \multicolumn{2}{c}{ Number of Individual Cases by Reaction Groups } \\
(Updated on 28 February 2020)
\end{tabular}

\subsection{Pharmacoeconomics}

A few economic evaluations were carried out in the US for tofacitinib, showing limited additional costs or even potential cost saving $[174,175]$. When given in monotherapy in MTX-intolerant patients, or with MTX in anti-TNF-intolerant patients, tofacitinib proved to be a less costly option compared to other bDMARDs as second-line treatment [176].

A treatment strategy with tofacitinib as either second- or third-line therapy after MTX may be a cheaper option, compared with the introduction of tofacitinib as fourth-line after cycling through 2 anti-TNF agents [177]. This finding was in line with a previous economic evaluation of tofacitinib vs. a set of biologic agents. This study showed that tofacitinib $5 \mathrm{mg}$ twice a day was a cost-effective treatment option for RA compared to adalimumab or etanercept. This was due to lower costs per patient when the drug was given in monotherapy or in combination with other cDMARDs in MTX-intolerant patients. The same was observed in anti-TNF-intolerant patients, in whom tofacitinib plus MTX was more cost-effective than adalimumab plus MTX [178]. Such results were confirmed by Kulikov et al., who assessed that therapy with tofacitinib could reduce the annual cost of RA treatment from $8846 €$ to $2037 €$ per patient in comparison with other bDMARDs [176]. According to a NICE Appraisal, tofacitinib in combination with MTX is a cost-effective use of National Health Service resources in patients with severe RA with inadequate response to cDMARDs, except for etanercept biosimilar in combination with MTX [179]. In patients with severe RA with inadequate response to bDMARDs, tofacitinib in combination with MTX was more cost-effective only in the group of RTX non-eligible patients. Tofacitinib monotherapy showed a less expensive, though slightly less effective, profile than that of comparators, and its use may replace the combo-therapy with MTX in MTX-intolerant patients. In MTX-intolerant patients, tofacitinib and tocilizumab monotherapy extendedly dominated 
a monotherapy with adalimumab and etanercept biosimilars [179]. Another recent study indicated tofacitinib as a dominant strategy (more effective and less costly) in patients affected by moderate to severe RA who are refractory to conventional and biologic drugs in second line and third line treatments, respectively [180], compared to other alternatives.

\section{Second Generation JAKi}

Considering the FDA and EMA approval of baricitinib and tofacitinib for the treatment of adults affected by moderate to severe anti-TNF resistant RA and for the treatment of moderate to severe MTX-refractory RA, active PsA and moderate to severe anti-TNF-refractory ulcerative colitis respectively, other JAKi have been developed for RA, reaching, in two cases, the market. Among them, upadacitinib was licensed in US and Europe and peficitinib authorized in Japan for the treatment of adult patients with moderate to severe active RA and an inadequate response or intolerance to MTX, while filgotinib and decernotinib are still under clinical investigation for RA. Itacitinib, a JAKi licensed for different therapeutic indications, has also been tested in RA in a phase II RCT. Current evidence concerning these compounds is reported in the next subparagraphs.

A synopsis of the chemical structure and the main pharmacological properties of the first and second generation JAKi aforementioned, are instead provided in Figure 3 and Table 6.<smiles>C[C@H]1CCN(C(=O)CC#N)C[C@H]1N(C)c1ncnc2[nH]ccc12</smiles>

Tofacitinib<smiles>O=C(Nc1nc2cccc(-c3ccc(CN4CCS(=O)(=O)CC4)cc3)n2n1)C1CC1</smiles>

Filgotinib<smiles>CCS(=O)(=O)N1CC(CC#N)(n2cc(-c3ncnc4[nH]ccc34)cn2)C1</smiles>

Baricitinib<smiles>CC[C@H]1CN(C(=O)NCC(F)(F)F)C[C@H]1c1cnc2cnc3[nH]ccc3n12</smiles>

Upadacitinib<smiles>NC(=O)c1cnc2[nH]ccc2c1NC1C2CC3CC1CC3(O)C2</smiles>

Peficitinib<smiles>CCC(C)(Nc1ccnc(-c2c[nH]c3ncccc23)n1)C(=O)NCC(F)(F)F</smiles>

Decernotinib

Figure 3. Molecular structure of first and second generation JAKi compared. 
Table 6. Synopsis of the main pharmacological properties of first and second generation JAKi. (JAKi, Janus kinase inhibitors; JAK, Janus kinase; TYK2, tyrosin kinase 2; sid, single dose; bid, twice daily; PK: pharmacokinetics; PD: pharmacodynamics; FDA: Food and Drug Administration; EMA: European Medicines Agency; Tmax: time to peak; bid: twice a day; sid; once a day; OAT: ornithine aminotransferase; CYP: cytochrome p450; US, United States; Eu, Europe; AUC, area under the curve; IC50, half maximal inhibitory concentration).

\begin{tabular}{|c|c|c|c|c|c|c|}
\hline \multirow{3}{*}{$\begin{array}{c}\text { Drug } \\
\text { active principle } \\
\text { brand name }\end{array}$} & \multicolumn{2}{|c|}{ First generation JAKi } & \multicolumn{4}{|c|}{ Second Generation JAKi } \\
\hline & Baricitinib & Tofacitinib & Upadacitinib & Peficitinib & Filgotinib & Decernotinib \\
\hline & Olumiant $^{\circledR}$ & Xeljanz ${ }^{\circledR}$ & Rinvoq $^{\mathrm{TM}}$ & Smyraf ${ }^{\circledR}$ & 1 & 1 \\
\hline other name & $\begin{array}{l}\text { INCB028050 } \\
\text { LY3009104 }\end{array}$ & СР-690,550 & ABT-494 & ASP015K, JNJ-54781532 & GLPG0634/GS-6034 & VX-509 \\
\hline target & $\begin{array}{l}\text { JAK1 } \\
\text { JAK2 }\end{array}$ & $\begin{array}{l}\text { JAK1 } \\
\text { JAK3 } \\
\text { JAK2 } \\
\text { TYK2 }\end{array}$ & JAK1 & $\begin{array}{l}\text { JAK3 } \\
\text { JAK1 }\end{array}$ & JAK1 & JAK3 \\
\hline Dose & $2 \mathrm{mg}$ sid & $5 \mathrm{mg}$ bid & $15 \mathrm{mg}$ sid & $\begin{array}{l}150 \mathrm{mg} \text { sid or } 100 \mathrm{mg} \\
\text { depending on the patient's } \\
\text { condition }\end{array}$ & $100 \mathrm{mg}$ or $200 \mathrm{mg}$ sid & 50-150 mg bid \\
\hline renal insufficiency & $\begin{array}{l}1 \mathrm{mg} \text { once daily in patients } \\
\text { with creatinine clearance } \\
\text { between } 30 \text { and } 60 \mathrm{~mL} / \mathrm{min} \\
\text { Not recommended in } \\
\text { patients with creatinine } \\
\text { clearance }<30 \mathrm{~mL} / \mathrm{min}\end{array}$ & $\begin{array}{l}\text { No dose adjustment in patients } \\
\text { with mild }(50-80 \mathrm{~mL} / \mathrm{min}) \text { or } \\
\text { moderate }(30-49 \mathrm{~mL} / \mathrm{min}) \text { renal } \\
\text { impairment } \\
5 \text { mg once daily in patient with } \\
\text { severe renal impairment } \\
(<30 \mathrm{~mL} / \mathrm{min})\end{array}$ & $\begin{array}{l}\text { No dose adjustment in } \\
\text { patients with mild, moderate } \\
\text { or severe renal impairment } \\
\text { Not tested in subjects with } \\
\text { end stage renal disease }\end{array}$ & $\begin{array}{l}\text { No dose adjustment required } \\
\text { in patients with renal } \\
\text { impairment }\end{array}$ & l & l \\
\hline liver failure & $\begin{array}{l}\text { No dose adjustment in } \\
\text { patients with mild or } \\
\text { moderate hepatic } \\
\text { impairment Not } \\
\text { recommended in patients } \\
\text { with severe hepatic } \\
\text { impairment }\end{array}$ & $\begin{array}{l}\text { No dose adjustment in patients } \\
\text { with mild (Child Pugh A) hepatic } \\
\text { impairment } \\
5 \mathrm{mg} \text { once daily recommended in } \\
\text { patient with moderate hepatic } \\
\text { function (<Child Pugh B) } \\
\text { Not recommended for use in } \\
\text { patients with severe hepatic } \\
\text { function (Child Pugh C) }\end{array}$ & $\begin{array}{l}\text { No dose adjustment in } \\
\text { patients with mild (Child } \\
\text { Pugh A) or moderate (Child } \\
\text { Pugh B) hepatic impairment } \\
\text { Not recommended in } \\
\text { patients with severe hepatic } \\
\text { impairment (Child Pugh C) }\end{array}$ & $\begin{array}{l}50 \mathrm{mg} \text { sid in patients with } \\
\text { moderate liver dysfunction } \\
\text { Contraindicated in patient } \\
\text { with severe liver dysfunction }\end{array}$ & l & / \\
\hline $\begin{array}{l}\text { development stage for } \\
\text { rheumatoid arthritis }\end{array}$ & Approved in $\sim 50$ countries & Approved in $\sim 80$ countries & Approved in US and Eu & $\begin{array}{l}\text { Approved in Japan } \\
\text { Under regulatory review in } \\
\text { South Korea and Taiwan } \\
\text { Under clinical development } \\
\text { in China }\end{array}$ & $\begin{array}{l}\text { Under regulatory review is } \\
\text { US, EU and Japan }\end{array}$ & Development discontinued \\
\hline approval & $\begin{array}{l}\text { FDA approval: yes (2018) } \\
\text { EMA approval: yes (2017) }\end{array}$ & $\begin{array}{l}\text { FDA approval: yes (2012) } \\
\text { EMA approval: yes (2017) }\end{array}$ & $\begin{array}{l}\text { FDA approval: yes (2019) } \\
\text { EMA approval: yes (2019) }\end{array}$ & $\begin{array}{l}\text { FDA approval: no } \\
\text { EMA approval: no } \\
\text { Japan approval: yes (2019) }\end{array}$ & $\begin{array}{l}\text { FDA approval: no } \\
\text { EMA approval: no }\end{array}$ & $\begin{array}{l}\text { FDA approval: no } \\
\text { EMA approval: no }\end{array}$ \\
\hline
\end{tabular}


Table 6. Cont

\begin{tabular}{|c|c|c|c|c|c|c|}
\hline Drug & \multicolumn{2}{|c|}{ First generation JAKi } & \multicolumn{4}{|c|}{ Second Generation JAKi } \\
\hline safety & $\begin{array}{l}\text { Most frequent: throat and } \\
\text { nose infections; herpes } \\
\text { simplex virus infection; } \\
\text { infections causing a sick } \\
\text { stomach or diarrhea; } \\
\text { urinary infections; } \\
\text { pneumonia; } \\
\text { thrombocytosis nausea; } \\
\text { Uncommon: leukopenia; } \\
\text { increase in serum creatine } \\
\text { kinase; high serum levels of } \\
\text { triglycerides; acne; weight } \\
\text { gain }\end{array}$ & $\begin{array}{l}\text { Most frequent: upper and lower } \\
\text { airway infections; influenza; } \\
\text { herpes zoster virus infection; } \\
\text { urinary tract infections; } \\
\text { abdominal pain; vomiting; } \\
\text { diarrhea; nausea; gastritis; rash; } \\
\text { headache; anemia; leukopenia; } \\
\text { hyper-transaminasemia } \\
\text { Uncommon: tuberculosis; } \\
\text { diverticulitis; pyelonephritis; } \\
\text { cellulitis; herpes simplex virus } \\
\text { infection; viral gastroenteritis } \\
\text { and other viral infections; blood } \\
\text { creatinine increase; blood } \\
\text { cholesterol increase; low density } \\
\text { lipoprotein increase; weight } \\
\text { increase } \\
\text { Rare: sepsis; disseminated } \\
\text { tuberculosis } \\
\text { involving bones and other } \\
\text { organs; other unusual infections; } \\
\text { joint infection }\end{array}$ & $\begin{array}{l}\text { Most frequent: upper } \\
\text { respiratory tract infections } \\
\text { (common cold, sinus } \\
\text { infections); nausea; cough; } \\
\text { fever } \\
\text { Uncommon: serious } \\
\text { infections; malignancies; } \\
\text { thrombosis; gastrointestinal } \\
\text { perforations; altered } \\
\text { laboratory parameters; } \\
\text { embryo-fetal toxicity } \\
\text { Rare: major adverse cardiac } \\
\text { events pulmonary embolism; } \\
\text { venous thromboembolism }\end{array}$ & $\begin{array}{l}\text { Most frequent: } \\
\text { nasopharyngitis; herpes } \\
\text { zoster virus infection; blood } \\
\text { creatine kinase increase; } \\
\text { lymphopenia } \\
\text { Uncommon: pneumonia; } \\
\text { pharyngitis; epipharyngitis; } \\
\text { upper respiratory tract } \\
\text { infections bronchitis; } \\
\text { influenza; cystitis } \\
\text { Rare: sepsis; gastrointestinal } \\
\text { perforation }\end{array}$ & $\begin{array}{l}\text { Most frequent: } \\
\text { nasopharyngitis; nausea; } \\
\text { bronchitis; headache; upper } \\
\text { respiratory tract infection } \\
\text { Uncommon: major adverse } \\
\text { cardiac events pulmonary } \\
\text { embolism; herpes zoster } \\
\text { virus infection; deep vein } \\
\text { thrombosis }\end{array}$ & $\begin{array}{l}\text { Most frequent: nausea; } \\
\text { headache; nasopharyngitis; } \\
\text { diarrhea; upper respiratory } \\
\text { tract infections; blood } \\
\text { cholesterol increase; } \\
\text { alanine aminotransferase } \\
\text { increase Uncommon: } \\
\text { serious infections }\end{array}$ \\
\hline $\begin{array}{l}\text { Licensed therapeutic } \\
\text { indications }\end{array}$ & $\operatorname{Tmax} 1.5 \mathrm{~h} ; \mathrm{t1} / 212.5 \mathrm{~h}$ & $\begin{array}{l}\text { Jont Infection } \\
\text { rheumatoid arthritis, psoriatic } \\
\text { arthritis, ulcerative colitis }\end{array}$ & $\operatorname{Tmax} 2-4 \mathrm{~h} ; \mathrm{t1} / 2$ 8-14h & $\begin{array}{l}\text { Tmax } 1.1-2.1 \mathrm{~h} ; \mathrm{t} 1 / 2 \\
9.9-16.2 \mathrm{~h} \\
\text { (after multiple } 30-200 \mathrm{mg} \\
\text { twice daily dosages) }\end{array}$ & $\begin{array}{l}\text { Under regulatory review } \\
\text { for rheumatoid arthritis } \\
\text { Tmax } 0,5-3 \mathrm{~h} \text {; } \mathrm{t} 1 / 2 \\
3.82-10.9 \mathrm{~h} \text { (after } \\
\text { single/multiple twice daily } \\
25-450 \mathrm{mg} \text { dosages) } \\
\text { Tmax } 1-2 ; \mathrm{t} 1 / 2 \text { (after } \\
\text { single/multiple twice daily } \\
\text { 30-300 } \mathrm{mg} \text { dosages) }\end{array}$ & N.A. \\
\hline drug interactions & $\begin{array}{l}\text { OAT3 inhibitors and } \\
\text { CYP3A4 inhibitors (e.g., } \\
\text { ketoconazole) and inducers } \\
\text { (e.g., rifampicin) }\end{array}$ & $\begin{array}{l}\text { IC50JAK1 } 3.2 \mathrm{nM} \text {; } \\
\text { IC50JAK2 } 4.1 \mathrm{nM} \text {; } \\
\text { IC50JAK3 } 1.6 \mathrm{nM} \text {; } \\
\text { IC50TYK2 } 34 \mathrm{nM} \\
\text { CYP3A4 inhibitors (e.g., } \\
\text { ketoconazole), medicinal } \\
\text { products that result in both } \\
\text { moderate inhibition of CYP3A4 } \\
\text { as well as potent inhibition of } \\
\text { CYP2C19 (e.g., fluconazole) and } \\
\text { CYP inducers }\end{array}$ & $\begin{array}{l}\text { IC50JAK1 45 nM; IC50JAK2 } \\
\text { 109 nM; IC50JAK3 } 2.1 \mu \mathrm{M} ; \\
\text { IC50TYK2 4.7 } \mu \mathrm{M}\end{array}$ & $\begin{array}{l}\text { IC50JAK1 } 3.9 \mathrm{nM} \text {; IC50JAK2 } \\
5.0 \mathrm{nM} \text {; } \\
\text { IC50JAK3 } 0.71 \mathrm{nM} \text {; IC50Tyk2 } \\
\text { 4.8 nM } \\
\text { Verapamil (P-glycoprotein } \\
\text { inhibitor that increase AUC } \\
\text { and Cmax of peficitinib by } \\
\text { 27-39\%) } \\
\text { No clinically significant } \\
\text { interaction with methotrexate } \\
\text { and rosuvastatin }\end{array}$ & $\begin{array}{l}\text { IC50JAK1 } 10 \mathrm{nM} \text {; IC50JAK2 } \\
\text { 28 nM; IC50JAK3 } 810 \mathrm{nM} ; \\
\text { IC50Tyk2 } 110 \mathrm{nM}\end{array}$ & $\begin{array}{l}\text { IC50JAK1 } 10 \mathrm{nM} \text {; IC50JAK2 } \\
\text { 10 nM; IC50JAK3 } 2.5 \mathrm{nM} \text {; } \\
\text { IC50TYK2 } 10 \mathrm{nM}\end{array}$ \\
\hline
\end{tabular}




\subsection{Upadacitinib}

Upadacitinib (IUPAC name: 3S,4R)-3-ethyl-4-(1,5,7,10-tetrazatricyclo[7.3.0.02,6]dodeca-2(6),3,7,9, 11-pentaen-12-yl)-N-(2,2,2-trifluoroethyl)pyrrolidine-1-carboxamide) was developed as a JAK1-selective inhibitor by exploiting differences in the non-conserved domains outside the active sites of JAK1 and JAK2. In cellular assays, upadacitinib displays 60 and 100 fold selectivity for JAK1 over JAK2 and for JAK1 over JAK3, respectively [181]. The drug was approved by FDA, and, more recently, by EMA, at a dosage of $15 \mathrm{mg}$ once daily, for adults with moderately to severely active RA who fail to adequately respond or are intolerant to MTX [182]. Like first generation JAKi, it may be prescribed with or without MTX.

The efficacy of upadacitinib has been evaluated in two phase II trials (BALANCE 1 and BALANCE 2) [84,183], one phase IIb/III trial (SELECT-SUNRISE) [184] and five phase III RCTs (SELECT-NEXT, SELECT-BEYOND, SELECT-MONOTHERAPY, SELECT-EARLY, SELECT-COMPARE) [185-190]. The phase III trial SELECT-CHOICE, comparing upadacitinib and abatacept in RA patients with an inadequate response to $\mathrm{c} / \mathrm{bDMARDs}$ is ongoing, and results have not published yet.

Results from BALANCE 1 and BALANCE 2 [84,183], enrolling anti-TNF failing and MTX-failing patients respectively, showed rapid, dose-dependent improvements in RA signs and symptoms, with a similar safety and tolerability profile to those of other JAKi.

Phase III RCTs recruited patients with inadequate response to at least one cDMARD, including MTX (SELECT-NEXT, SELECT-MONOTHERAPY and SELECT-COMPARE) $[185,187,189]$, and patients with inadequate response or intolerance to bDMARDs (SELECT-BEYOND) [186]. Patients were randomly assigned to received once-daily extended-release formulations of upadacitinib $15 \mathrm{or} 30 \mathrm{mg}$ or placebo for at least 12 weeks. Overall, results of these studies showed a rapid statistically significant improvement in the ACR20 response as early as week 1, and in the ACR50 and ACR70 responses from week 2 onward with upadacitinib 15 and $30 \mathrm{mg}[185,186]$. DAS28-CRP and CDAI scores were significantly improved with both the two upadacitinib doses, with $40-50 \%$ of patients achieving low disease activity by week 12 . Quality of life, physical function, fatigue, severity, and duration of morning stiffness were also significantly improved in upadacitinib arms regardless of the dose. Of note, in the SELECT-BEYOND trial, recruiting 498 RA patients failing previous lines with biologics (anti-TNF and anti-IL-6R agents), the efficacy outcomes were achieved in the upadacitinib arm vs. placebo regardless of the number or kind of previously received treatments [186].

In the SELECT-MONOTHERAPY phase III RCT [187], upadacitinib monotherapy led to statistically significant improvements in clinical and functional outcomes vs. the continuation of MTX in MTX-resistant patients. A higher and statistically significant proportion of patients receiving both the two upadacitinib doses achieved DAS28-CRP low disease activity or remission compared to those assigned to MTX alone.

In the SELECT-COMPARE trial, upadacitinib, at a dose of $15 \mathrm{mg}$ once daily, outperformed adalimumab in the achievement of ACR50, HAQ and DAS28-CRP responses at week 12 in MTX-refractory RA patients. Furthermore, a higher percentage of upadacitinib-assigned patients were in low disease activity or remission at week 26 compared to the adalimumab arm $[189,191]$.

The safety profile of upadacitinib was in line with that of non-selective JAKi. Adverse events in BALANCE 1 and 2 increased in a dose-dependent manner but were mostly mild and included infections (the most common adverse events), nausea, headache, transient increase in serum transaminases and in lipid levels (both LDL and HDL with unchanged ratio) [84,183]. A dose-dependent decrease in the levels of hemoglobin (grade 3 and 4 anemia) was also noted, as well as a decrease in lymphocyte, NK cell and neutrophil count.

Serious infections occurred in the upadacitinib $30 \mathrm{mg}$ arms of the SELECT-NEXT and SELECT-BEYOND trials, but none had a fatal course [185,186]. An increased incidence of HZV reactivation was observed in all the upadacitinib treatment arms across the five trials, with two serious cases in the upadacitinib $30 \mathrm{mg}$ group in the SELECT-BEYOND study [186]. Two malignancies and one major MACE occurred in the upadacitinib $30 \mathrm{mg}$ arm of the SELECT-NEXT trial [185], whereas four 
malignancies and two MACEs were reported in the SELECT-BEYOND trial in upadacitinib arms [186]. Four cases of pulmonary embolism were also reported in the SELECT-BEYOND study, but all the patients had known additional risk factors. In the SELECT-COMPARE trial an increase in serum creatine phosphokinase $(\mathrm{CPK})$ was reported in subjects receiving upadacitinib but not in those treated with the active comparator [191]. Upadacitinib is metabolized by CYP enzymes, including CYP3A, but it can be safely taken with other CYP3A-metabolized drugs, including statins [192], which might be co-prescribed due to the paradoxical effect of JAKi on lipid transport. However, attention must be paid to the plausible synergistic effect of upadacitinib and statins in inducing CPK elevation and skeletal muscle damage.

\subsection{Peficitinib}

Peficitinib (IUPAC name: 4-[[(1R,3S)-5-hydroxy-2-adamantyl]amino]-1H-pyrrolo[2,3-b]pyridine-5carboxamide) is an oral JAKi approved in March 2019 in Japan for the treatment of RA in patients who have an inadequate response to conventional therapies [193]. The drug is still under pending development in the US and in Europe.

The recommended dose of peficitinib is $150 \mathrm{mg}$ or less, depending on patient's condition, in an after meal single daily administration [194].

Peficitinib displays a less target selectivity than other second generation JAKi. Together with tofacitinib, it is, in fact, considered a pan-JAK inhibitor with a higher selectivity for JAK3 (IC50 $=710 \mathrm{nmol} / \mathrm{mL}$ ) than for the other JAKs [94]. The low selectivity for JAK2 limits its effects on both red blood cells and platelets suggesting a good safety profile [195].

Findings from phase I studies on healthy volunteers demonstrated that peficitinib is rapidly absorbed in fasting condition. Tmax ranged from $1 \mathrm{~h}$ to $1.8 \mathrm{~h}$, depending on the dose, and pharmacokinetics was not significantly influenced by renal impairment [196]. Meals, instead, delay median Tmax from $1.5 \mathrm{~h}$ to $4.0 \mathrm{~h}$ and increase peficitinib exposure (AUC) by 27\% [197]. In addition, the high elimination half-life allows the administration of the drug once a day [198].

Two phase II studies, involving Japanese and non-Japanese patients, aimed to investigate the efficacy and safety of peficitinib in RA patients [198,199]. The studies showed a statistically significant improvement in the ACR20 response rate at week 12 and a similar number of adverse events compared with placebo. A third study, conducted in non-Japanese (North and Latin Americans) RA patients receiving peficitinib in combination with MTX, did not reach the prefixed endpoints due to a high rate of response in the placebo group [200].

The approval of peficitinib was based mainly on the results of two 52 week phase III studies (RAJ3 and RAJ4) [201,202], aiming to evaluate the efficacy and safety of peficitinib, at a single daily dose of $100 \mathrm{mg}$ or $150 \mathrm{mg}$ alone or in combination with cDMARDs, in RA patients non-responder to conventional therapies. The superiority of peficitinib over placebo was demonstrated in both RAJ3 and RAJ4 studies. At week 12, peficitinib clearly outperformed placebo in terms of ACR20 and ACR50 response rates in the RAJ3 study [201], while the ACR70 response was significantly achieved only in the $150 \mathrm{mg}$ peficitinib arm. In the RAJ4 trial, a significant change from baseline in mTSS at week 28 was also reported [202].

The safety profile was in line with that of other already available JAKi and no red flags presented during these studies.

\subsection{Filgotinib}

Filgotinib (IUPAC name: N-[5-[4-[(1,1-dioxo-1,4-thiazinan-4-yl)methyl]phenyl]-[1,2,4]triazolo [1,5-a]pyridin-2-yl]cyclopropanecarboxamide) was designed following a kinase-focused-high-throughput library screening, which identified triazolopyridines as JAK-1 selective catalytic inhibitors [203]. The drug, currently under regulatory review, potently and selectively inhibits JAK1 (IC50 = 629 $\mathrm{nmol} / \mathrm{mL}$ ) [94]. Due to its target selectivity, filgotinib is estimated to have a good efficacy and a better safety profile than unselective JAKi. In particular, as JAK1 is not involved in the signaling pathway of 
erythropoietin, colony-stimulating factor, and thrombopoietin, filgotinib should not increase the risk of anemia and thrombocytopenia [204].

The efficacy and safety of filgotinib in MTX-unresponsive RA patients were tested in two exploratory phase IIa trials [205], including a monocentric four-week proof of concept study and a multicentric four-week preliminary study. In the first trial, patients were randomized to receive filgotinib $200 \mathrm{mg}$ daily or placebo, whereas in the second one, they were randomly assigned to different doses of filgotinib ( $30 \mathrm{mg}, 75 \mathrm{mg}$, $150 \mathrm{mg}$, or $300 \mathrm{mg}$ once daily) or placebo. Both the studies evidenced a satisfactory efficacy profile of the drug. In the proof of concept study, a statistically significant number of patients achieved an ACR20 response compared to placebo. Furthermore, a reduction in serum CRP levels and in DAS28-CRP scores was also reported in the filgotinib-assigned arm. Conversely, the treatment with filgotinib was not associated with a significant improvement in the ACR20 response rate in the four-week preliminary study, although a trend was observed for the $300 \mathrm{mg}$ dose. No safety issues were reported.

These initial data together with those obtained from healthy volunteers paved the way for the development of a population's pharmacokinetic/pharmacodynamic model to be used for dose selection in phase IIb studies [206,207]. The pharmacodynamic effect of filgotinib is, in fact, given by the parent drug and its active metabolite. The latter derives from the loss of the cyclopropyl carboxylic acid group following the action of carboxylesterases [204]. Despite having a lower target selectivity for JAK1 compared to filgotinib (IC50 $=11.9 \mu \mathrm{mol} / \mathrm{ml}$ ), the active metabolite has an elimination half-life of $23 \mathrm{~h}$, allowing the administration of the compound in a single daily dose [205]. A wide dose range and different dosing regimens, with or without MTX, were investigated in 24-week dose finding phase IIb studies in patients with active RA despite the concomitant use of MTX (DARWIN 1 and DARWIN 2) [206,207]. Results showed that filgotinib at a dose of 100 or $200 \mathrm{mg}$ once daily, given either as mono- or combo-therapy, was efficacious and well tolerated. Recently, the published results of the 24 week FINCH2 phase III study confirmed the efficacy of filgotinib $100 \mathrm{mg}$ and $200 \mathrm{mg}$ once daily in RA patients refractory to one or more bDMARD [208]. No opportunistic infections, malignancies, or fatalities were recorded during the observational period.

\subsection{Decernotinib}

Decernotinib (IUPAC name: (2R)-2-methyl-2-[[2-(1H-pyrrolo[2,3-b]pyridin-3-yl)pyrimidin-4-yl] amino]-N-(2,2,2-trifluoroethyl)butanamide) is an oral selective JAK3 inhibitor whose development for the treatment of RA is presumed to have been discontinued. JAK3 is expressed in lymphoid cells and its blockade may prevent the signaling of several cytokines involved in autoimmunity, including IL-2, IL-4, IL-7, and IL-15 [209], without affecting red blood cells and platelets.

Decernotinib was discovered following a library screening of compounds targeting JAK3 and chemically modified in order to enhance its binding-affinity and potency [210]. The drug was tested in phase IIa and IIb RCTs as monotherapy [211] or in combination with MTX [212] or other cDMARDs [213]. When given as monotherapy in RA patients with uncontrolled disease despite the use of at least 1 cDMARD, decernotinib, at dosages of $25 \mathrm{mg}, 50 \mathrm{mg}, 100 \mathrm{mg}$, or $150 \mathrm{mg}$ twice a day, led to a significant improvement in the ACR20 response and DAS28-CRP scores at week 12 compared to placebo. Best benefits were observed in patients who received one of the 3 higher doses $(50 \mathrm{mg}, 100 \mathrm{mg}$, and $150 \mathrm{mg}$ ). Clinical remission, defined by a DAS28-CRP score $<2.6$, was significantly greater in patients assigned to decernotinib $100 \mathrm{mg}$ and $150 \mathrm{mg}$ compared to placebo. The administration of decernotinib at a dose of $150 \mathrm{mg}$ twice a day also resulted in better ACR50 and ACR70 response rates than those observed with placebo.

Dose titration studies showed that the ACR50 response was significantly higher with all the doses at week 12 and 24, while the achievement of the ACR70 response at week 12 was only significant with the doses of $150 \mathrm{mg}$ once a day and of $100 \mathrm{mg}$ twice a day [212].

Genovese et al. investigated the efficacy of the drug in the achievement of clinical and magnetic resonance imaging (MRI) outcomes in patients with inadequate DMARD response and randomly 
assigned to decernotinib (100 mg, $200 \mathrm{mg}$ or $300 \mathrm{mg}$ once daily) or placebo for 12 weeks [213]. Compared to placebo, the ACR20, DAS28-CRP and RA MRI scoring (RAMRIS) responses improved over 12 weeks across all the decernotinib dosages in a dose-dependent manner when combined with a stable cDMARD background.

The treatment with decernotinib was generally well tolerated. Adverse events were more frequent when the drug was administered at higher doses. The most common adverse events were nausea, headache, HZV reactivation, nasopharyngitis, diarrhea, upper respiratory trait infections, increased ALT serum levels, and hypercholesterolemia.

In the phase IIa RCT, the incidence of infections was similar between placebo and decernotinib assigned groups, but the frequency was higher with the 100 and $150 \mathrm{mg}$ doses compared to $50 \mathrm{mg}$ and $25 \mathrm{mg}$ doses. Five serious infections occurred, all in the decernotinib treatment arms, with two fatalities due to pneumonia and subarachnoid hemorrhage.

Twelve of the 13 serious infections reported in the phase IIb studies (decernotinib + MTX) occurred in decernotinib-treated patients (with nine cases of pneumonia/bronchitis), and included two fatalities due to pneumonia and cardiac failure. Other adverse events encompassed increases in serum lipids and creatinine and the decrease in lymphocyte blood count, all of which were dose-dependent.

As decernotinib is a potent inhibitor of CYP3A4, this may represent a limitation in its use when coprescribed with CYP3A4-metabolized medications, like statins.

\subsection{Itacitinib}

Itacitinib (INCB039110; Incyte Corporation, Wilmington, DE) (IUPAC name: 2-[1-[1-[3-fluoro-2-(trifluoromethyl)pyridine-4-carbonyl]piperid in-4-yl]-3-[4-(7H-pyrrolo[2,3-d]pyrimi din-4-yl)pyrazol-1-yl]azetidin-3-yl]acetonitrile) is a novel oral selective JAK1 inhibitor, approved in 2018 by EMA as an orphan drug for the treatment of graft-versus-host disease (GVHD) [214], and currently tested for other clinical indications, including oncologic and immunologic disorders. In RA, itacitinib has been tested in a phase II randomized, dose-ranging, placebo-controlled trial [215]. The study evaluated the efficacy of itacitinib $100 \mathrm{mg}$ twice a day, $200 \mathrm{mg}$ twice a day, and 300 and $600 \mathrm{mg}$ once daily vs. placebo in patients with active RA despite cDMARDs. The study showed that patients assigned to the highest dose had better clinical improvements and a sustained ACR20 response than patients in the other arms, regardless of background therapy or previous biologic experience. Responses were observed as early as at the first assessment time (14 days). Itacitinib was generally well tolerated. No grade 3 or grade 4 adverse events (AE) nor serious and opportunistic infections were reported. A dose-related increase in LDL was noted, though without any change in the HDL/LDL ratio. Safety data obtained from studies on GVHD patients treated with itacitinib suggest that no dose adjustment is required for a single dose of $300 \mathrm{mg}$ even in patients with severe renal impairment or end-stage renal disease [216]. Furthermore, studies on healthy participants showed that single doses ranging from 10 to $1000 \mathrm{mg}$ are safe from a cardiovascular point of view [217].

Nevertheless, to date, no registration trials have been designed for the use of itacitinib in RA.

\section{Concluding Discussion}

The JAK-STAT signaling pathway plays a central role in many physiopathological processes, including antimicrobial defense, hematopoiesis, post-natal growth and metabolism [71]. When activated in a canonical way, it mediates cytokine and growth factor intracellular signals; however, a non-canonical activation has also been described and associated with the epigenetic control of chromatin stability and with cell homeostasis [74]. Consequently, JAK-STAT dysregulation may be at the basis of many pathological conditions, ranging from solid and hematologic malignancies to insulin resistance, obesity and immune-mediated diseases [71,93,146,218,219]. Hence, several JAKi have been developed for the treatment of myeloproliferative and lymphoproliferative disorders, as well as for solid tumors [71].

More recently, the advent of the anti-rheumatic JAKi constituted a breakthrough in the therapeutic algorithm of RA and other inflammatory diseases, including spondyloarthritis and inflammatory 
bowel diseases. The panorama of JAKi is constantly enriching with new incoming molecules designed to be more specific on targeted cells and pathways, thus resulting in a better efficacy and safety profile. Compared to their biologic counterparts, JAKi differ in the route of administration, safety and efficacy profile and costs of manufacturing. Given the evidence of superiority or non-inferiority of JAKi vs. adalimumab emerging from RCTs [125,156,190], the 2020 updated EULAR therapeutic guidelines [113] recommended the use of $\mathrm{JAKi}$ as an alternative to biologics in RA patients refractory to cDMARDs and having poor prognostic factors, as well as in those failing a previous biologic or synthetic line [24]. A preference for biologics or JAKi should be accorded based on contraindications, monotherapy need or cost issues. Furthermore, data from RCTs evidenced a rapid and maintained efficacy of JAKi regardless of the co-prescription of MTX or other CDMARDs, and the safety profile of JAKi appeared in line with that of other authorized treatments for RA. However, some side effects, including thromboembolic events or HZV reactivation, seem to specifically occur with this class of medications. Due to a higher target selectivity, second generation JAKi may display a better safety profile.

Nevertheless, several questions remain unanswered and should be inscribed in future research agendas: (1) the identification of biomarkers (e.g., ACPA or RF positivity) predicting a better response to JAKi; (2) the duration of JAKi treatment and issues related to a dose-reduction strategy or discontinuation in patients being in low disease activity or remission; (3) the interference played, in the long term, by other CYP-metabolized drugs on JAKi pharmacokinetic profile; (4) the efficacy and safety derived from a JAKi cycling strategy and from the combination of JAKi with bDMARDs; (5) the efficacy and safety of JAKi compared to non-anti-TNF biologics. Indirect comparison data from network meta-analysis and patient cohort registries have partly addressed the latter point with regard to tofacitinib [160-165], but no evidence currently exists for other JAKi.

Growing experience on already marketed JAKi and cumulative experimental findings on novel compounds are expected to clarify many of these aspects in the next years.

Author Contributions: G.B., G.F., J.A., L.D.C., R.R., and S.B. drafted the original manuscript and tables, performed the bibliographic research and drew the figures. R.T. drew the figures, helped in writing and implemented the manuscript performing a second literature research. J.A., R.T. and F.S. critically reviewed the manuscript. All authors have read and agreed to the published version of the manuscript.

Funding: This research received no external funding.

Conflicts of Interest: The authors declare that they do not have any conflict of interests.

\section{References}

1. Areskoug-Josefsson, K.; Öberg, U. A literature review of the sexual health of women with rheumatoid arthritis. Musculoskelet. Care 2009, 7, 219-226. [CrossRef] [PubMed]

2. Ahlmen, M.; Svensson, B.; Albertsson, K.; Forslind, K.; Hafström, I. Influence of gender on assessments of disease activity and function in early rheumatoid arthritis in relation to radiographic joint damage. Ann. Rheum. Dis. 2009, 69, 230-233. [CrossRef] [PubMed]

3. Grassi, W.; De Angelis, R.; Lamanna, G.; Cervini, C. The clinical features of rheumatoid arthritis. Eur. J. Radiol. 1998, 27, S18-S24. [CrossRef]

4. Young, A.; Koduri, G. Extra-Articular manifestations and complications of rheumatoid arthritis. Best Pract. Res. Clin. Rheumatol. 2007, 21, 907-927. [CrossRef]

5. Generali, E.; Cantarini, L.; Selmi, C. Ocular Involvement in Systemic Autoimmune Diseases. Clin. Rev. Allergy Immunol. 2015, 49, 263-270. [CrossRef]

6. Rugarli, C. Medicina Interna Sistematica. Sesta Edizione; Elsevier Srl: Milan, Italy, 2010; pp. 1710-1712.

7. Scherer, H.U.; Häupl, T.; Burmester, G.R. The etiology of rheumatoid arthritis. J. Autoimmun. 2020, 110, 102400. [CrossRef]

8. Horta-Baas, G.; Romero-Figueroa, M.D.S.; Montiel-Jarquín, A.J.; Pizano-Zárate, M.L.; García-Mena, J.; Ramírez-Durán, N. Intestinal Dysbiosis and Rheumatoid Arthritis: A Link between Gut Microbiota and the Pathogenesis of Rheumatoid Arthritis. J. Immunol. Res. 2017, 2017, 4835189. [CrossRef] 
9. Silman, A.J.; Pearson, J.E. Epidemiology and genetics of rheumatoid arthritis. Arthritis Res. 2002, 4, S265-S272. [CrossRef]

10. Okada, Y.; The RACI Consortium; Wu, D.; Trynka, G.; Raj, T.; Terao, C.; Ikari, K.; Kochi, Y.; Ohmura, K.; Suzuki, A.; et al. Genetics of rheumatoid arthritis contributes to biology and drug discovery. Nature 2013, 506, 376-381. [CrossRef]

11. O'Shea, J.J.; Schwartz, D.M.; Villarino, A.V.; Gadina, M.; McInnes, I.; Laurence, A. The JAK-STAT pathway: Impact on human disease and therapeutic intervention. Annu. Rev. Med. 2015, 66, 311-328. [CrossRef]

12. Banerjee, S.; Biehl, A.; Gadina, M.; Hasni, S.A.; Schwartz, D.M. JAK-STAT Signaling as a Target for Inflammatory and Autoimmune Diseases: Current and Future Prospects. Drugs 2017, 77, 521-546. [CrossRef] [PubMed]

13. Viatte, S.; Plant, D.; Han, B.; Fu, B.; Yarwood, A.; Thomson, W.; Symmons, D.P.M.; Worthington, J.; Young, A.; Hyrich, K.L.; et al. Association of HLA-DRB1 haplotypes with rheumatoid arthritis severity, mortality, and treatment response. JAMA Am. Med. Assoc. 2015, 313, 1645-1656. [CrossRef] [PubMed]

14. Klareskog, L.; Malmström, V.; Lundberg, K.; Padyukov, L.; Alfredsson, L. Smoking, citrullination and genetic variability in the immunopathogenesis of rheumatoid arthritis. Semin. Immunol. 2011, 23, 92-98. [CrossRef]

15. Millar, K.; Lloyd, S.M.; McLean, J.S.; Batty, G.D.; Burns, H.; Cavanagh, J.; Deans, K.A.; Ford, I.; McConnachie, A.; McGinty, A.; et al. Personality, Socio-Economic Status and Inflammation: Cross-Sectional, Population-Based Study. PLoS ONE 2013, 8, e58256. [CrossRef]

16. Honda, K.; Littman, D.R. The microbiome in infectious disease and inflammation. Annu. Rev. Immunol. 2012, 30, 759-795. [CrossRef]

17. Ebringer, A.; Wilson, C. HLA molecules, bacteria and autoimmunity. J. Med. Microbiol. 2000, 49, 305-311. [CrossRef] [PubMed]

18. Viatte, S.; Plant, D.; Raychaudhuri, S. Genetics and epigenetics of rheumatoid arthritis. Nat. Rev. Rheumatol. 2013, 9, 141-153. [CrossRef]

19. Evangelatos, G.; Fragoulis, G.E.; Koulouri, V.; Lambrou, G.I. MicroRNAs in rheumatoid arthritis: From pathogenesis to clinical impact. Autoimmun. Rev. 2019, 18, 102391. [CrossRef]

20. Gaffen, S.L. The role of interleukin-17 in the pathogenesis of rheumatoid arthritis. Curr. Rheumatol. Rep. 2009, 11, 365-370. [CrossRef]

21. Silverman, G.J.; Carson, D.A. Roles of B cells in rheumatoid arthritis. Arthritis Res. Ther. 2003, 5, S1-S6. [CrossRef]

22. McInnes, I.B.; Schett, G. Cytokines in the pathogenesis of rheumatoid arthritis. Nat. Rev. Immunol. 2007, 7, 429-442. [CrossRef] [PubMed]

23. McInnes, I.; Schett, G. The Pathogenesis of Rheumatoid Arthritis. N. Engl. J. Med. 2011, 365, $2205-2219$. [CrossRef] [PubMed]

24. Smolen, J.S.; Landewé, R.B.M.; Bijlsma, J.W.J.; Burmester, G.R.; Dougados, M.; Kerschbaumer, A.; McInnes, I.B.; Sepriano, A.; Van Vollenhoven, R.F.; De Wit, M.; et al. EULAR recommendations for the management of rheumatoid arthritis with synthetic and biological disease-modifying antirheumatic drugs: 2019 update. Ann. Rheum. Dis. 2020, 79, 685-699. [CrossRef] [PubMed]

25. Singh, J.A.; Saag, K.G.; Bridges, S.L.; Akl, E.A.; Bannuru, R.R.; Sullivan, M.C.; Vaysbrot, E.; McNaughton, C.; Osani, M.; Shmerling, R.; et al. 2015 American College of Rheumatology Guideline for the Treatment of Rheumatoid Arthritis. Arthritis Rheumatol. 2015, 68, 1-25. [CrossRef] [PubMed]

26. Saag, K.G.; Koehnke, R.; Caldwell, J.R.; Brasington, R.; Burmeister, L.F.; Zimmerman, B.; Kohler, J.A.; Furst, D.E. Low dose long-term corticosteroid therapy in rheumatoid arthritis: An analysis of serious adverse events. Am. J. Med. 1994, 96, 115-123. [CrossRef]

27. Donahue, K.E.; Gartlehner, G.; Jonas, D.E.; Lux, L.J.; Thieda, P.; Hansen, R.; Morgan, L.C.; Lohr, K.N. Systematic Review: Comparative Effectiveness and Harms of Disease-Modifying Medications for Rheumatoid Arthritis. Ann. Intern. Med. 2008, 148, 124. [CrossRef] [PubMed]

28. Crofford, L.J. Use of NSAIDs in treating patients with arthritis. Arthritis Res. Ther. 2013, 15, S2. [CrossRef]

29. Curtis, J.R.; Singh, J.A. Use of biologics in rheumatoid arthritis: Current and emerging paradigms of care. Clin. Ther. 2011, 33, 679-707. [CrossRef]

30. Aletaha, D.; Smolen, J.S. Diagnosis and Management of Rheumatoid Arthritis. JAMA Am. Med. Assoc. 2018, 320, 1360-1372. [CrossRef] 
31. Wang, D.; Li, Y.; Liu, Y.; Shi, G. The use of biologic therapies in the treatment of rheumatoid arthritis. Curr. Pharm. Biotechnol. 2014, 15, 542-548. [CrossRef]

32. Yamaoka, K. Janus kinase inhibitors for rheumatoid arthritis. Curr. Opin. Chem. Biol. 2016, 32, $29-33$. [CrossRef] [PubMed]

33. Emery, P.; Pope, J.E.; Kruger, K.; Lippe, R.; Demasi, R.; Lula, S.; Kola, B. Efficacy of Monotherapy with Biologics and JAK Inhibitors for the Treatment of Rheumatoid Arthritis: A Systematic Review. Adv. Ther. 2018, 35, 1535-1563. [CrossRef] [PubMed]

34. Villarino, A.V.; Kanno, Y.; O'Shea, J.J. Mechanisms and consequences of Jak-STAT signaling in the immune system. Nat. Immunol. 2017, 18, 374-384. [CrossRef] [PubMed]

35. Zhang, H.; Li, H.S.; Watowich, S.S. Jak-STAT Signaling Pathways. Encycl. Immunobiol. 2016, 3, $134-145$. [CrossRef]

36. Shuai, K.; Liu, B. Regulation of gene-activation pathways by PIAS proteins in the immune system. Nat. Rev. Immunol. 2005, 5, 593-605. [CrossRef]

37. Atzeni, F.; Talotta, R.; Nucera, V.; Marino, F.; Gerratana, E.; Sangari, D.; Masala, I.F.; Sarzi-Puttini, P. Adverse events, clinical considerations and management recommendations in rheumatoid arthritis patients treated with JAK inhibitors. Expert Rev. Clin. Immunol. 2018, 14, 945-956. [CrossRef]

38. Virtanen, A.T.; Haikarainen, T.; Raivola, J.; Silvennoinen, O. Selective JAKinibs: Prospects in Inflammatory and Autoimmune Diseases. BioDrugs 2019, 33, 15-32. [CrossRef]

39. Morris, R.; Kershaw, N.J.; Babon, J.J. The molecular details of cytokine signaling via the JAK/STAT pathway. Protein Sci. 2018, 27, 1984-2009. [CrossRef]

40. Witalisz-Siepracka, A.; Klein, K.; Prinz, D.; Leidenfrost, N.; Schabbauer, G.; Dohnal, A.; Sexl, V. Loss of JAK1 Drives Innate Immune Deficiency. Front. Immunol. 2019, 9. [CrossRef]

41. Rochman, Y.; Kashyap, M.; Robinson, G.W.; Sakamoto, K.; Gomez-Rodriguez, J.; Wagner, K.-U.; Leonard, W.J. Thymic stromal lymphopoietin-mediated STAT5 phosphorylation via kinases JAK1 and JAK2 reveals a key difference from IL-7-induced signaling. Proc. Natl. Acad. Sci. USA 2010, 107, 19455-19460. [CrossRef]

42. Demoulin, J.-B.; Uyttenhove, C.; Lejeune, D.; Mui, A.; Groner, B.; Renauld, J.C. STAT5 activation is required for interleukin-9-dependent growth and transformation of lymphoid cells. Cancer Res. 2000, 60, 3971-3977. [PubMed]

43. Kovanen, P.E.; Leonard, W.J. Cytokines and immunodeficiency diseases: Critical roles of the gammac-dependent cytokines interleukins 2, 4, 7, 9, 15, and 21, and their signaling pathways. Immunol. Rev. 2004, 202, 67-83. [CrossRef] [PubMed]

44. Caldenhoven, E.; Van Dijk, T.; Raaijmakers, J.A.M.; Lammers, J.-W.J.; Koenderman, L.; De Groot, R.P. Activation of the STAT3/Acute Phase Response Factor Transcription Factor by Interleukin-5. J. Biol. Chem. 1995, 270, 25778-25784. [CrossRef]

45. Chen, X.H.; Patel, B.K.R.; Wang, L.-M.; Frankel, M.; Ellmore, N.; Flavell, R.A.; LaRochelle, W.J.; Pierce, J.H. Jak1 Expression Is Required for Mediating Interleukin-4-induced Tyrosine Phosphorylation of Insulin Receptor Substrate and Stat6 Signaling Molecules. J. Biol. Chem. 1997, 272, 6556-6560. [CrossRef] [PubMed]

46. Stark, G.R.; Darnell, J.E. The JAK-STAT pathway at twenty. Immunity 2012, 36, 503-514. [CrossRef]

47. Heinrich, P.C.; Behrmann, I.; Müller-Newen, G.; Schaper, F.; Graeve, L. Interleukin-6-type cytokine signalling through the gp130/Jak/STAT pathway. Biochem. J. 1998, 334, 297-314. [CrossRef]

48. Donnelly, R.P.; Dickensheets, H.; Finbloom, D.S. The Interleukin-10 Signal Transduction Pathway and Regulation of Gene Expression in Mononuclear Phagocytes. J. Interferon Cytokine Res. 1999, 19, 563-573. [CrossRef]

49. Watford, W.T.; Hissong, B.D.; Bream, J.H.; Kanno, Y.; Muul, L.; O'Shea, J.J. Signaling by IL-12 and IL-23 and the immunoregulatory roles of STAT4. Immunol. Rev. 2004, 202, 139-156. [CrossRef]

50. Chiba, Y.; Goto, K.; Misawa, M. Interleukin-13-induced activation of signal transducer and activator of transcription 6 is mediated by an activation of Janus kinase 1 in cultured human bronchial smooth muscle cells. Pharmacol. Rep. 2012, 64, 454-458.

51. Trivella, D.B.B.; Ferreira-Junior, J.R.; Dumoutier, L.; Renauld, J.-C.; Polikarpov, I. Structure and function of interleukin-22 and other members of the interleukin-10 family. Cell. Mol. Life Sci. 2010, 67, 2909-2935. [CrossRef] 
52. Andrés, R.M.; Hald, A.; Johansen, C.; Kragballe, K.; Iversen, L. Studies of Jak/STAT3 expression and signalling in psoriasis identifies STAT3-Ser727 phosphorylation as a modulator of transcriptional activity. Exp. Dermatol. 2013, 22, 323-328. [CrossRef]

53. Wolk, K.; Haugen, H.S.; Xu, W.; Witte, E.; Waggie, K.; Anderson, M.; Baur, E.V.; Witte, K.; Warszawska, K.; Philipp, S.; et al. IL-22 and IL-20 are key mediators of the epidermal alterations in psoriasis while IL-17 and IFN- $\gamma$ are not. J. Mol. Med. 2009, 87, 523-536. [CrossRef] [PubMed]

54. Buchert, M.; Burns, C.J.; Ernst, M. Targeting JAK kinase in solid tumors: Emerging opportunities and challenges. Oncogene 2015, 35, 939-951. [CrossRef] [PubMed]

55. Gaffen, S.L.; Jain, R.; Garg, A.V.; Cua, D.J. The IL-23-IL-17 immune axis: From mechanisms to therapeutic testing. Nat. Rev. Immunol. 2014, 14, 585-600. [CrossRef] [PubMed]

56. Andoh, A.; Shioya, M.; Nishida, A.; Bamba, S.; Tsujikawa, T.; Kim-Mitsuyama, S.; Fujiyama, Y. Expression of IL-24, an Activator of the JAK1/STAT3/SOCS3 Cascade, Is Enhanced in Inflammatory Bowel Disease. J. Immunol. 2009, 183, 687-695. [CrossRef]

57. Alunno, A.; Padjen, I.; Fanouriakis, A.; Boumpas, D.T. Pathogenic and Therapeutic Relevance of JAK/STAT Signaling in Systemic Lupus Erythematosus: Integration of Distinct Inflammatory Pathways and the Prospect of Their Inhibition with an Oral Agent. Cells 2019, 8, 898. [CrossRef]

58. Zhang, Q.; Putheti, P.; Zhou, Q.; Liu, Q.; Gao, W. Structures and biological functions of IL-31 and IL-31 receptors. Cytokine Growth Factor Rev. 2008, 19, 347-356. [CrossRef]

59. Darnell, J.; Kerr, I.; Stark, G. Jak-STAT pathways and transcriptional activation in response to IFNs and other extracellular signaling proteins. Science 1994, 264, 1415-1421. [CrossRef]

60. Abdolvahab, M.H.; Mofrad, M.K.; Schellekens, H. Interferon Beta: From Molecular Level to Therapeutic Effects. Int. Rev. Cell Mol. Biol. 2016, 326, 343-372. [CrossRef]

61. Morelli, M.; Scarponi, C.; Mercurio, L.; Facchiano, F.; Pallotta, S.; Madonna, S.; Girolomoni, G.; Albanesi, C. Selective Immunomodulation of Inflammatory Pathways in Keratinocytes by the Janus Kinase (JAK) Inhibitor Tofacitinib: Implications for the Employment of JAK-Targeting Drugs in Psoriasis. J. Immunol. Res. 2018, 2018, 7897263. [CrossRef]

62. Biethahn, S.; Alves, F.; Wilde, S.; Hiddemann, W.; Spiekermann, K. Expression of granulocyte colony-stimulating factor- and granulocyte-macrophage colony-stimulating factor-associated signal transduction proteins of the JAK/STAT pathway in normal granulopoiesis and in blast cells of acute myelogenous leukemia. Exp. Hematol. 1999, 27, 885-894. [CrossRef]

63. Al-Shami, A.; Mahanna, W.; Naccache, P.H. Granulocyte-Macrophage Colony-stimulating Factor-activated Signaling Pathways in Human Neutrophils. J. Biol. Chem. 1998, 273, 1058-1063. [CrossRef]

64. Morita, H.; Tahara, T.; Matsumoto, A.; Kato, T.; Miyazaki, H.; Ohashi, H. Functional analysis of the cytoplastic domain of the human $\mathrm{Mpl}$ receptor for tyrosine-phosphorylation of the signaling molecules, proliferation and differentiation. FEBS Lett. 1996, 395, 228-234. [CrossRef]

65. Smit, L.S.; Meyer, D.J.; Billestrup, N.; Norstedt, G.; Schwartz, J.; Carter-Su, C. The role of the growth hormone $(\mathrm{GH})$ receptor and JAK1 and JAK2 kinases in the activation of Stats 1, 3, and 5 by GH. Mol. Endocrinol. 1996, 10, 519-533. [CrossRef] [PubMed]

66. Kuhrt, D.; Wojchowski, N.M. Emerging EPO and EPO receptor regulators and signal transducers. Blood 2015, 125, 3536-3541. [CrossRef] [PubMed]

67. Nagata, Y.; Nagahisa, H.; Nagasawa, T.; Todokoro, K. Regulation of megakaryocytopoiesis by thrombopoietin and stromal cells. Leukemia 1997, 11, 435-438.

68. Wada, N.; Hirako, S.; Takenoya, F.; Kageyama, H.; Okabe, M.; Shioda, S. Leptin and its receptors. J. Chem. Neuroanat. 2014, 61, 191-199. [CrossRef]

69. Lehtonen, A.; Matikainen, S.; Miettinen, M.; Julkunen, I. Granulocyte-Macrophage colony-stimulating factor (GM-CSF)-induced STAT5 activation and target-gene expression during human monocyte/macrophage differentiation. J. Leukoc. Biol. 2002, 71, 511-519.

70. Herrera, S.C.; Bach, E.A. JAK/STAT signaling in stem cells and regeneration: From Drosophila to vertebrates. Development 2019, 146, dev167643. [CrossRef]

71. Roskoski, R. Janus kinase (JAK) inhibitors in the treatment of inflammatory and neoplastic diseases. Pharmacol. Res. 2016, 111, 784-803. [CrossRef]

72. Aittomäki, S.; Pesu, M. Therapeutic Targeting of the JAK/STAT Pathway. Basic Clin. Pharmacol. Toxicol. 2013, 114, 18-23. [CrossRef] [PubMed] 
73. Majoros, A.; Platanitis, E.; Kernbauer-Hölzl, E.; Rosebrock, F.; Müller, M.; Decker, T. Canonical and Non-Canonical Aspects of JAK-STAT Signaling: Lessons from Interferons for Cytokine Responses. Front. Immunol. 2017, 8, 258. [CrossRef]

74. Li, W.X. Canonical and non-Canonical JAK-STAT signaling. Trends Cell Biol. 2008, 18, 545-551. [CrossRef] [PubMed]

75. Sehgal, P.B. Paradigm shifts in the cell biology of STAT signaling. Semin. Cell Dev. Biol. 2008, 19, 329-340. [CrossRef] [PubMed]

76. Silver-Morse, L.; Li, W.X. JAK-STAT in heterochromatin and genome stability. JAK-STAT 2013, 2, e26090. [CrossRef] [PubMed]

77. Choy, E.H.S.; Miceli-Richard, C.; González-Gay, M.A.; Sinigaglia, L.; Schlichting, D.E.; Meszaros, G.; de la Torre, L.; Schulze-Koops, H. The effect of JAK1/JAK2 inhibition in rheumatoid arthritis: Efficacy and safety of baricitinib. Clin. Exp. Rheumatol. 2019, 37, 694-704.

78. Liu, T.; Zhang, L.; Joo, D.; Sun, S.-C. NF-кB signaling in inflammation. Signal Transduct. Target. Ther. 2017, 2, 17023. [CrossRef]

79. Yarilina, A.; Xu, K.; Chen, J.; Ivashkiv, L.B. TNF activates calcium-nuclear factor of activated T cells (NFAT)c1 signaling pathways in human macrophages. Proc. Natl. Acad. Sci. USA 2011, 108, 1573-1578. [CrossRef]

80. McFarland, B.C.; Gray, G.K.; Nozell, S.E.; Hong, S.W.; Benveniste, E.N. Activation of the NF-kB pathway by the STAT3 inhibitor JSI-124 in human glioblastoma cells. Mol. Cancer Res. 2013, 11, 494-505. [CrossRef]

81. Manukyan, I.; Galatioto, J.; Mascareno, E.; Bhaduri, S.; Siddiqui, M. Cross-Talk between calcineurin/NFAT and Jak/STAT signalling induces cardioprotective $\alpha$ B-crystallin gene expression in response to hypertrophic stimuli. J. Cell. Mol. Med. 2009, 14, 1707-1716. [CrossRef]

82. Hodge, J.A.; Kawabata, T.T.; Krishnaswami, S.; Clark, J.D.; Telliez, J.-B.; Dowty, M.E.; Menon, S.; Lamba, M.; Zwillich, S. The mechanism of action of tofacitinib-An oral Janus kinase inhibitor for the treatment of rheumatoid arthritis. Clin. Exp. Rheumatol. 2016, 34, 318-328.

83. Westhovens, R. Clinical efficacy of new JAK inhibitors under development. Just more of the same? Rheumatology 2019, 58, i27-i33. [CrossRef]

84. Kremer, J.M.; Emery, P.; Camp, H.S.; Friedman, A.; Wang, L.; Othman, A.A.; Khan, N.; Pangan, A.L.; Jungerwirth, S.; Keystone, E.C. A Phase IIb Study of ABT-494, a Selective JAK-1 Inhibitor, in Patients with Rheumatoid Arthritis and an Inadequate Response to Anti-Tumor Necrosis Factor Therapy. Arthritis Rheumatol. 2016, 68, 2867-2877. [CrossRef] [PubMed]

85. European Medicines Agency. Olumiant EPAR Product Information; EMA: London, UK, 2018.

86. European Medicines Agency. Xeljanz EPAR Product Information; EMA: London, UK, 2018.

87. Wollenhaupt, J.; Lee, E.B.; Curtis, J.R.; Silverfield, J.; Terry, K.; Soma, K.; Mojcik, C.; Demasi, R.; Strengholt, S.; Kwok, K.; et al. Safety and efficacy of tofacitinib for up to 9.5 years in the treatment of rheumatoid arthritis: Final results of a global, open-label, long-term extension study. Arthritis Res. 2019, 21, 89. [CrossRef]

88. Harigai, M. Growing evidence of the safety of JAK inhibitors in patients with rheumatoid arthritis. Rheumatology 2019, 58, i34-i42. [CrossRef]

89. Winthrop, K.L. The emerging safety profile of JAK inhibitors in rheumatic disease. Nat. Rev. Rheumatol. 2017, 13, 234-243. [CrossRef] [PubMed]

90. Frisdal, E.; Lesnik, P.; Olivier, M.; Robillard, P.; Chapman, M.J.; Huby, T.; Guerin, M.; Le Goff, W. Interleukin-6 Protects Human Macrophages from Cellular Cholesterol Accumulation and Attenuates the Proinflammatory Response. J. Biol. Chem. 2011, 286, 30926-30936. [CrossRef] [PubMed]

91. Charles-Schoeman, C.; Fleischmann, R.; Davignon, J.; Schwartz, H.; Turner, S.M.; Beysen, C.; Milad, M.; Hellerstein, M.K.; Luo, Z.; Kaplan, I.V.; et al. Potential Mechanisms Leading to the Abnormal Lipid Profile in Patients With Rheumatoid Arthritis Versus Healthy Volunteers and Reversal by Tofacitinib. Arthritis Rheumatol. 2015, 67, 616-625. [CrossRef]

92. Jagpal, A.; Navarro-Millán, I. Cardiovascular co-morbidity in patients with rheumatoid arthritis: A narrative review of risk factors, cardiovascular risk assessment and treatment. BMC Rheumatol. 2018, 2, 10. [CrossRef] [PubMed]

93. Olivera, P.A.; Lasa, J.S.; Bonovas, S.; Danese, S.; Peyrin-Biroulet, L. Safety of Janus Kinase Inhibitors in Patients With Inflammatory Bowel Diseases or Other Immune-mediated Diseases: A Systematic Review and Meta-Analysis. Gastroenterology 2020, 158, 1554-1573.e12. [CrossRef] 
94. Jegatheeswaran, J.; Turk, M.; Pope, J.E. Comparison of Janus kinase inhibitors in the treatment of rheumatoid arthritis: A systemic literature review. Immunotherapy 2019, 11, 737-754. [CrossRef] [PubMed]

95. Mayence, A.; Eynde, J.J.V. Baricitinib: A 2018 Novel FDA-Approved Small Molecule Inhibiting Janus Kinases. Pharmaceuticals 2019, 12, 37. [CrossRef]

96. Olumiant, T.M. Product Monograph; Eli Lilly Canada Inc.: Toronto, ON, Canada, 2018; Revised on 9 April 2020.

97. Babon, J.J.; Lucet, I.S.; Murphy, J.M.; Nicola, N.A.; Varghese, L.N. The molecular regulation of Janus kinase (JAK) activation. Biochem. J. 2014, 462, 1-13. [CrossRef] [PubMed]

98. Kubo, S.; Nakayamada, S.; Sakata, K.; Kitanaga, Y.; Ma, X.; Lee, S.; Ishii, A.; Yamagata, K.; Nakano, K.; Tanaka, Y. Janus Kinase Inhibitor Baricitinib Modulates Human Innate and Adaptive Immune System. Front. Immunol. 2018, 9. [CrossRef]

99. Murakami, K.; Kobayashi, Y.; Uehara, S.; Suzuki, T.; Koide, M.; Yamashita, T.; Nakamura, M.; Takahashi, N.; Kato, H.; Udagawa, N.; et al. A Jak1/2 inhibitor, baricitinib, inhibits osteoclastogenesis by suppressing RANKL expression in osteoblasts in vitro. PLoS ONE 2017, 12, e0181126. [CrossRef]

100. Fleischmann, R.; Takeuchi, T.; Schiff, M.; Schlichting, D.; Xie, L.; Issa, M.; Stoykov, I.; Lisse, J.; Martinez-Osuna, P.; Rooney, T.; et al. Efficacy and safety of long-term baricitinib with and without methotrexate for the treatment of rheumatoid arthritis: Experience with baricitinib monotherapy continuation or after switching from methotrexate monotherapy or baricitinib plus methotrexate. Arthritis Rheumatol. 2019. [CrossRef] [PubMed]

101. Shi, J.G.; Chen, X.; Lee, F.; Emm, T.; Scherle, P.A.; Lo, Y.; Punwani, N.; Williams, W.V.; Yeleswaram, S. The pharmacokinetics, pharmacodynamics, and safety of baricitinib, an oral JAK $1 / 2$ inhibitor, in healthy volunteers. J. Clin. Pharmacol. 2014, 54, 1354-1361. [CrossRef]

102. Zhang, X.; Chua, L.; Ernest, C.; Macias, W.; Rooney, T.; Tham, L.S. Dose/Exposure-Response Modeling to Support Dosing Recommendation for Phase III Development of Baricitinib in Patients with Rheumatoid Arthritis. CPT Pharmacomet. Syst. Pharmacol. 2017, 6, 804-813. [CrossRef]

103. Olumiant. Monograph for Professionals-Drugs.com. 2019. Available online: https://www.accessdata.fda. gov/drugsatfda_docs/nda/2018/207924Orig1s000ClinPharmR.pdf (accessed on 12 April 2017).

104. Kawalec, P.; Śladowska, K.; Malinowska-Lipień, I.; Brzostek, T.; Kózka, M. New alternative in the treatment of rheumatoid arthritis: Clinical utility of baricitinib. Ther. Clin. Risk Manag. 2019, 15, 275-284. [CrossRef]

105. Fleischmann, R.; Schiff, M.; Van Der Heijde, D.; Ramos-Remus, C.; Spindler, A.; Stanislav, M.; Zerbini, C.A.F.; Gurbuz, S.; Dickson, C.; De Bono, S.; et al. Baricitinib, Methotrexate, or Combination in Patients With Rheumatoid Arthritis and No or Limited Prior Disease-Modifying Antirheumatic Drug Treatment. Arthritis Rheumatol. 2017, 69, 506-517. [CrossRef]

106. Taylor, P.; Keystone, E.; van der Heijde, D.; Tanaka, Y.; Ishii, T.; Emoto, K.; Yang, L.; Arora, V.; Gaich, C.L.; Rooney, T.; et al. Baricitinib Versus Placebo or Adalimumab in Patients with Active Rheumatoid Arthritis (RA) and an Inadequate Response to Background Methotrexate Therapy: Results of a Phase 3 Study Peter. Arthritis Rheumatol. 2015, 67, 26-30.

107. Dougados, M.; Van Der Heijde, D.; Chen, Y.-C.; Greenwald, M.; Drescher, E.; Liu, J.; Beattie, S.; De La Torre, I.; Rooney, T.; Schlichting, D.; et al. LB0001 Baricitinib, an Oral Janus Kinase (JAK)1/JAK2 Inhibitor, in Patients with Active Rheumatoid Arthritis (RA) and An Inadequate Response to CDMARD Therapy: Results of the Phase 3 RA-Build Study. Ann. Rheum. Dis. 2015, 74. [CrossRef]

108. Genovese, M.; Kremer, J.; Zamani, O.; Ludivico, C.; Krogulec, M.; Xie, L.; Beattie, S.; Koch, A.; Cardillo, T.; Rooney, T.; et al. OP0029 Baricitinib, An Oral Janus Kinase (JAK)1/JAK2 Inhibitor, in Patients with Active Rheumatoid Arthritis (RA) and an Inadequate Response to TNF Inhibitors: Results of the Phase 3 RA-Beacon Study. Ann. Rheum. Dis. 2015, 74, 75-76. [CrossRef]

109. European Medicines Agency. Olumiant (Baricitinib): EU Assessment Report; European Medicines Agency: London, UK, 2016.

110. Van Der Heijde, D.; Dougados, M.; Chen, Y.-C.; Greenwald, M.; Drescher, E.; Klar, R.; Xie, L.; De La Torre, I.; Rooney, T.P.; Witt, S.L.; et al. Effects of baricitinib on radiographic progression of structural joint damage at 1 year in patients with rheumatoid arthritis and an inadequate response to conventional synthetic disease-modifying antirheumatic drugs. RMD Open 2018, 4, e000662. [CrossRef] [PubMed]

111. Van Der Heijde, D.; Schiff, M.; Tanaka, Y.; Xie, L.; Meszaros, G.; Ishii, T.; Casillas, M.; Ortmann, R.A.; Emery, P. Low rates of radiographic progression of structural joint damage over 2 years of baricitinib treatment in patients with rheumatoid arthritis. RMD Open 2019, 5, e000898. [CrossRef] 
112. Keystone, E.C.; Taylor, P.C.; Tanaka, Y.; Gaich, C.; DeLozier, A.M.; Dudek, A.; Zamora, J.V.; Cobos, J.A.C.; Rooney, T.; De Bono, S.; et al. Patient-reported outcomes from a phase 3 study of baricitinib versus placebo or adalimumab in rheumatoid arthritis: Secondary analyses from the RA-BEAM study. Ann. Rheum. Dis. 2017, 76, 1853-1861. [CrossRef]

113. Smolen, J.S.; Landewé, R.; Bijlsma, J.; Burmester, G.; Chatzidionysiou, K.; Dougados, M.; Nam, J.; Ramiro, S.; Voshaar, M.; Van Vollenhoven, R.; et al. EULAR recommendations for the management of rheumatoid arthritis with synthetic and biological disease-modifying antirheumatic drugs: 2016 update. Ann. Rheum. Dis. 2017, 76, 960-977. [CrossRef]

114. Takeuchi, T.; Genovese, M.C.; Haraoui, B.; Li, Z.; Xie, L.; Klar, R.; Pinto-Correia, A.; Otawa, S.; Lopez-Romero, P.; De La Torre, I.; et al. Dose reduction of baricitinib in patients with rheumatoid arthritis achieving sustained disease control: Results of a prospective study. Ann. Rheum. Dis. 2018, 78, 171-178. [CrossRef]

115. Prakken, B.; Albani, S.; Martini, A. Juvenile idiopathic arthritis. Lancet 2011, 377, 2138-2149. [CrossRef]

116. Kochi, Y.; Suzuki, A.; Yamada, R.; Yamamoto, K. Ethnogenetic heterogeneity of rheumatoid arthritis-Implications for pathogenesis. Nat. Rev. Rheumatol. 2010, 6, 290-295. [CrossRef]

117. Alamanos, Y.; Drosos, A.A. Epidemiology of adult rheumatoid arthritis. Autoimmun. Rev. 2005, 4, $130-136$. [CrossRef]

118. Harrold, L.R.; Harrington, J.T.; Curtis, J.R.; Furst, D.E.; Bentley, M.J.; Shan, Y.; Reed, G.; Kremer, J.; Greenberg, J.D. Prescribing practices in a US cohort of rheumatoid arthritis patients before and after publication of the American College of Rheumatology treatment recommendations. Arthritis Rheumatol. 2012, 64, 630-638. [CrossRef]

119. Tanaka, Y.; Atsumi, T.; Amano, K.; Harigai, M.; Ishii, T.; Kawaguchi, O.; Rooney, T.P.; Akashi, N.; Takeuchi, T. Efficacy and safety of baricitinib in Japanese patients with rheumatoid arthritis: Subgroup analyses of four multinational phase 3 randomized trials. Mod. Rheumatol. 2017, 28, 583-591. [CrossRef] [PubMed]

120. Tanaka, Y.; Emoto, K.; Cai, Z.; Aoki, T.; Schlichting, D.; Rooney, T.; Macias, W. Efficacy and Safety of Baricitinib in Japanese Patients with Active Rheumatoid Arthritis Receiving Background Methotrexate Therapy: A 12-week, Double-blind, Randomized Placebo-controlled Study. J. Rheumatol. 2016, 43, 504-511. [CrossRef] [PubMed]

121. Tanaka, Y.; Ishii, T.; Cai, Z.; Schlichting, D.; Rooney, T.; Macias, W. Efficacy and safety of baricitinib in Japanese patients with active rheumatoid arthritis: A 52-week, randomized, single-blind, extension study. Mod. Rheumatol. 2017, 28, 20-29. [CrossRef] [PubMed]

122. Harigai, M.; Takeuchi, T.; Smolen, J.S.; Winthrop, K.L.; Nishikawa, A.; Rooney, T.P.; Saifan, C.G.; Issa, M.; Isaka, Y.; Akashi, N.; et al. Safety profile of baricitinib in Japanese patients with active rheumatoid arthritis with over 1.6 years median time in treatment: An integrated analysis of Phases 2 and 3 trials. Mod. Rheumatol. 2019, 30, 36-43. [CrossRef] [PubMed]

123. Greenwald, M.K.; Fidelus-Gort, R.; Levy, R. A randomized dose-ranging, placebo-controlled study of INCB028050, a selective JAK1 and JAK2 inhibitor in subjects with active rheumatoid arthritis [abstract]. Arthritis Rheumatol. 2010, 62 (Suppl. 10), 2172.

124. Keystone, E.; Taylor, P.C.; Drescher, E.; Schlichting, D.E.; Beattie, S.D.; Berclaz, P.-Y.; Lee, C.H.; Fidelus-Gort, R.K.; Luchi, M.E.; Rooney, T.P.; et al. Safety and efficacy of baricitinib at 24 weeks in patients with rheumatoid arthritis who have had an inadequate response to methotrexate. Ann. Rheum. Dis. 2014, 74, 333-340. [CrossRef] [PubMed]

125. Taylor, P.C.; Keystone, E.; Van Der Heijde, D.; Weinblatt, M.E.; Morales, L.D.C.; Gonzaga, J.R.; Yakushin, S.; Ishii, T.; Emoto, K.; Beattie, S.; et al. Baricitinib versus Placebo or Adalimumab in Rheumatoid Arthritis. N. Engl. J. Med. 2017, 376, 652-662. [CrossRef]

126. Dougados, M.; Van Der Heijde, D.; Chen, Y.-C.; Greenwald, M.; Drescher, E.; Liu, J.; Beattie, S.; Witt, S.; De La Torre, I.; Gaich, C.; et al. Baricitinib in patients with inadequate response or intolerance to conventional synthetic DMARDs: Results from the RA-BUILD study. Ann. Rheum. Dis. 2016, 76, 88-95. [CrossRef]

127. Genovese, M.C.; Kremer, J.M.; Zamani, O.; Ludivico, C.; Krogulec, M.; Xie, L.; Beattie, S.D.; Koch, A.E.; Cardillo, T.E.; Rooney, T.P.; et al. Baricitinib in Patients with Refractory Rheumatoid Arthritis. N. Engl. J. Med. 2016, 374, 1243-1252. [CrossRef] [PubMed] 
128. Smolen, J.S.; Genovese, M.C.; Takeuchi, T.; Hyslop, D.L.; Macias, W.L.; Rooney, T.; Chen, L.; Dickson, C.L.; Camp, J.R.; Cardillo, T.E.; et al. Safety Profile of Baricitinib in Patients with Active Rheumatoid Arthritis with over 2 Years Median Time in Treatment. J. Rheumatol. 2018, 46, 7-18. [CrossRef] [PubMed]

129. Xie, W.; Xiao, S.; Zhang, Z. Response to: 'Impact of Janus kinase inhibitors on the risk of cardiovascular events in patients with rheumatoid arthritis: Systematic review and meta-analysis of randomised controlled trials' by Lee and Song. Ann. Rheum. Dis. 2019, 78, 1048-1054. [CrossRef]

130. Schlueter, M.; Finn, E.; Díaz, S.; Dilla, T.; Inciarte-Mundo, J.; Fakhouri, W. Cost-effectiveness analysis of baricitinib versus adalimumab for the treatment of moderate-to-severe rheumatoid arthritis in Spain. Clin. Outcomes Res. 2019, 11, 395-403. [CrossRef]

131. Ravasio, R.; Antonelli, S.; Rogai, V.; Fakhouri, W.; Capron, J.P.; Losi, S. Mean cost per number needed to treat of baricitinib versus adalimumab in the treatment of rheumatoid arthritis in Italy. Glob. Reg. Health Technol. Assess. 2018, 2018, 1-6. [CrossRef]

132. Wehler, E.; Boytsov, N.; Nicolay, C.; Herrera-Restrepo, O.; Kowal, S. A Budget Impact and Cost Per Additional Responder Analysis for Baricitinib for the Treatment of Moderate-to-Severe Rheumatoid Arthritis in Patients with an Inadequate Response to Tumor Necrosis Factor Inhibitors in the USA. PharmacoEconomics 2019, 38, 39-56. [CrossRef]

133. Ren, S.; Bermejo, I.; Simpson, E.; Wong, R.; Scott, D.L.; Young, A.; Stevenson, M. Baricitinib for Previously Treated Moderate or Severe Rheumatoid Arthritis: An Evidence Review Group Perspective of a NICE Single Technology Appraisal. PharmacoEconomics 2018, 36, 769-778. [CrossRef]

134. Food and Drug Administration. Product Monograph, Xeljanz (Tofacitinib); FDA: New York, NY, USA, 2018.

135. Dowty, M.E.; Lin, J.; Ryder, T.F.; Wang, W.; Walker, G.S.; Vaz, A.; Chan, G.L.; Krishnaswami, S.; Prakash, C. The Pharmacokinetics, Metabolism, and Clearance Mechanisms of Tofacitinib, a Janus Kinase Inhibitor, in Humans. Drug Metab. Dispos. 2014, 42, 759-773. [CrossRef]

136. Li, Y.; Yuan, L.; Yang, J.; Lei, Y.; Zhang, H.; Xia, L.; Shen, H.; Lu, J. Changes in Serum Cytokines May Predict Therapeutic Efficacy of Tofacitinib in Rheumatoid Arthritis. Mediat. Inflamm. 2019, 2019, 5617431. [CrossRef]

137. Kim, J.; Tomalin, L.; Lee, J.; Fitz, L.J.; Berstein, G.; Da Rosa, J.C.; Garcet, S.; Lowes, M.; Valdez, H.; Wolk, R.; et al. Reduction of Inflammatory and Cardiovascular Proteins in the Blood of Patients with Psoriasis: Differential Responses between Tofacitinib and Etanercept after 4 Weeks of Treatment. J. Investig. Dermatol. 2018, 138, 273-281. [CrossRef]

138. Gao, W.; McCormick, J.; Orr, C.; Connolly, M.; Fearon, U.; Veale, D.J. Tofacitinib regulates synovial angiogenesis in psoriatic arthritis through induction of negative feedback inhibitors. Arthritis Rheumatol. 2014, 66, S1222-S1223.

139. Gao, W.; McGarry, T.; Orr, C.; McCormick, J.; Veale, D.J.; Fearon, U. Tofacitinib regulates synovial inflammation in psoriatic arthritis, inhibiting STAT activation and induction of negative feedback inhibitors. Ann. Rheum. Dis. 2015, 75, 311-315. [CrossRef]

140. Kubo, S.; Yamaoka, K.; Kondo, M.; Yamagata, K.; Zhao, J.; Iwata, S.; Tanaka, Y. The JAK inhibitor, tofacitinib, reduces the $\mathrm{T}$ cell stimulatory capacity of human monocyte-derived dendritic cells. Ann. Rheum. Dis. 2013, 73, 2192-2198. [CrossRef] [PubMed]

141. Van Vollenhoven, R.F.; Tanaka, Y.; Lamba, M.; Collinge, M.; Hendrikx, T.; Hirose, T.; Toyoizumi, S.; Hazra, A.; Krishnaswami, S. THU0178 Relationship Between NK Cell Count and Important Safety Events in Rheumatoid Arthritis Patients Treated with Tofacitinib. Ann. Rheum. Dis. 2015, 74, 258.3-259. [CrossRef]

142. Weinhold, K.J.; Bukowski, J.F.; Brennan, T.V.; Noveck, R.J.; Staats, J.; Lin, L.; Stempora, L.; Hammond, C.; Wouters, A.; Mojcik, C.F.; et al. Reversibility of peripheral blood leukocyte phenotypic and functional changes after exposure to and withdrawal from tofacitinib, a Janus kinase inhibitor, in healthy volunteers. Clin. Immunol. 2018, 191, 10-20. [CrossRef]

143. Rizzi, M.; Lorenzetti, R.; Fischer, K.; Staniek, J.; Janowska, I.; Troilo, A.; Strohmeier, V.; Erlacher, M.; Kunze, M.; Bannert, B.; et al. Impact of tofacitinib treatment on human B-cells in vitro and in vivo. J. Autoimmun. 2017, 77, 55-66. [CrossRef]

144. Yoshida, H.; Hunter, C.A. The Immunobiology of Interleukin-27. Annu. Rev. Immunol. 2015, 33, 417-443. [CrossRef]

145. Fasching, P.; Stradner, M.; Graninger, W.; Dejaco, C.F.J. Therapeutic Potential of Targeting the Th17/Treg Axis in Autoimmune Disorders. Molecules 2017, 22, 134. [CrossRef] 
146. Damsky, W.; King, B. JAK inhibitors in dermatology: The promise of a new drug class. J. Am. Acad. Dermatol. 2017, 76, 736-744. [CrossRef]

147. Fleischmann, R.; Kremer, J.M.; Cush, J.; Schulze-Koops, H.; Connell, C.A.; Bradley, J.D.; Gruben, D.; Wallenstein, G.V.; Zwillich, S.H.; Kanik, K.S. Placebo-Controlled Trial of Tofacitinib Monotherapy in Rheumatoid Arthritis. N. Engl. J. Med. 2012, 367, 495-507. [CrossRef]

148. Lee, E.B.; Fleischmann, R.; Hall, S.; Wilkinson, B.; Bradley, J.D.; Gruben, D.; Koncz, T.; Krishnaswami, S.; Wallenstein, G.V.; Zang, C.; et al. Tofacitinib versus Methotrexate in Rheumatoid Arthritis. N. Engl. J. Med. 2014, 370, 2377-2386. [CrossRef] [PubMed]

149. Kremer, J.; Li, Z.-G.; Hall, S.; Fleischmann, R.; Genovese, M.; Martín-Mola, E.; Isaacs, J.D.; Gruben, D.; Wallenstein, G.; Krishnaswami, S.; et al. Tofacitinib in combination with nonbiologic disease-modifying antirheumatic drugs in patients with active rheumatoid arthritis: A randomized trial. Ann. Intern. Med. 2013, 159, 253-261. [CrossRef]

150. Van Der Heijde, D.; Tanaka, Y.; Fleischmann, R.; Keystone, E.C.; Kremer, J.M.; Zerbini, C.; Cardiel, M.H.; Cohen, S.B.; Nash, P.; Song, Y.-W.; et al. Tofacitinib (CP-690,550) in patients with rheumatoid arthritis receiving methotrexate: Twelve-month data from a twenty-four-month phase III randomized radiographic study. Arthritis Rheumatol. 2013, 65, 559-570. [CrossRef] [PubMed]

151. Van Vollenhoven, R.F.; Fleischmann, R.; Cohen, S.; Lee, E.B.; Meijide, J.A.G.; Wagner, S.; Forejtová, Š.; Zwillich, S.H.; Gruben, D.; Koncz, T.; et al. Tofacitinib or Adalimumab versus Placebo in Rheumatoid Arthritis. N. Engl. J. Med. 2012, 367, 508-519. [CrossRef]

152. Burmester, G.R.; Blanco, R.; Charles-Schoeman, C.; Wollenhaupt, J.; Zerbini, C.; Benda, B.; Gruben, D.; Wallenstein, G.; Krishnaswami, S.; Zwillich, S.H.; et al. Tofacitinib (CP-690,550) in combination with methotrexate in patients with active rheumatoid arthritis with an inadequate response to tumour necrosis factor inhibitors: A randomised phase 3 trial. Lancet 2013, 381, 451-460. [CrossRef]

153. Yamanaka, H.; Tanaka, Y.; Takeuchi, T.; Sugiyama, N.; Yuasa, H.; Toyoizumi, S.; Morishima, Y.; Hirose, T.; Zwillich, S.H. Tofacitinib, an oral Janus kinase inhibitor, as monotherapy or with background methotrexate, in Japanese patients with rheumatoid arthritis: An open-label, long-term extension study. Arthritis Res. 2016, 18, 34. [CrossRef]

154. Gabay, C.; Emery, P.; Van Vollenhoven, R.; Dikranian, A.; Alten, R.; Pavelka, K.; Klearman, M.; Musselman, D.; Agarwal, S.; Green, J.; et al. Tocilizumab monotherapy versus adalimumab monotherapy for treatment of rheumatoid arthritis (ADACTA): A randomised, double-blind, controlled phase 4 trial. Lancet 2013, 381, 1541-1550. [CrossRef]

155. Fleischmann, R.; Mysler, E.; Hall, S.; Kivitz, A.J.; Moots, R.J.; Luo, Z.; Demasi, R.; Soma, K.; Zhang, R.; Takiya, L.; et al. Efficacy and safety of tofacitinib monotherapy, tofacitinib with methotrexate, and adalimumab with methotrexate in patients with rheumatoid arthritis (ORAL Strategy): A phase 3b/4, double-blind, head-to-head, randomised controlled trial. Lancet 2017, 390, 457-468. [CrossRef]

156. Fleischmann, R.; Mysler, E.; Hall, S.; Kivitz, A.; Moots, R.; Luo, Z.; Tatulych, S.; Demasi, R.; Soma, K.; Zhang, R.; et al. Tofacitinib with and without Methotrexate Versus Adalimumab with Methotrexate for the Treatment of Rheumatoid Arthritis: Patient-Reported Outcomes from a Phase 3b/4 Randomized Trial. Arthritis Rheumatol. 2017, 69, 10.

157. van der Heijde, D.; Wollenhaupt, J.; Cohen, S.B.; Strengholt, S.; Terry, K.; Kwok, K.; DeMasi, R.; Lazariciu, L.; Wang, L. Assessment of radiographic progression in patients with rheumatoid arthritis treated with tofacitinib: Data from an open-label long-term extension study over 3 years. Arthritis Rheumatol. 2017, 69, 10.

158. Ruperto, N.; Brunner, H.I.; Zuber, Z.; Tzaribachev, N.; Kingsbury, D.J.; Foeldvari, I.; Horneff, G.; Smolewska, E.; Vehe, R.K.; Hazra, A.; et al. Pharmacokinetic and safety profile of tofacitinib in children with polyarticular course juvenile idiopathic arthritis: Results of a phase 1, open-label, multicenter study. Pediatr. Rheumatol. 2017, 15, 86. [CrossRef]

159. Huang, Z.; Lee, P.Y.; Yao, X.; Zheng, S.; Li, T. Tofacitinib Treatment of Refractory Systemic Juvenile Idiopathic Arthritis. Pediatrics 2019, 143, e20182845. [CrossRef] [PubMed]

160. Singh, J.A.; Hossain, A.; Ghogomu, E.T.; Kotb, A.; Christensen, R.; Mudano, A.S.; Maxwell, L.J.; Shah, N.P.; Tugwell, P.; Wells, G.A. Biologics or tofacitinib for rheumatoid arthritis in incomplete responders to methotrexate or other traditional disease-modifying anti-rheumatic drugs: A systematic review and network meta-analysis. Cochrane Database Syst. Rev. 2016, 2016. [CrossRef] [PubMed] 
161. Singh, J.A.; Hossain, A.; Ghogomu, E.T.; Mudano, A.S.; Maxwell, L.J.; Buchbinder, R.; Lopez-Olivo, M.A.; Suarez-Almazor, M.E.; Tugwell, P.; Wells, G.A. Biologics or tofacitinib for people with rheumatoid arthritis unsuccessfully treated with biologics: A systematic review and network meta-analysis. Cochrane Database Syst. Rev. 2017, 2017, 818. [CrossRef]

162. Vieira, M.-C.; Zwillich, S.H.; Jansen, J.P.; Smiechowski, B.; Spurden, D.; Wallenstein, G.V. Tofacitinib Versus Biologic Treatments in Patients With Active Rheumatoid Arthritis Who Have Had an Inadequate Response to Tumor Necrosis Factor Inhibitors: Results From a Network Meta-analysis. Clin. Ther. 2016, 38, 2628-2641.e5. [CrossRef]

163. Bergrath, E.; Gerber, R.A.; Gruben, D.; Lukic, T.; Makin, C.; Wallenstein, G.V. Tofacitinib versus Biologic Treatments in Moderate-to-Severe Rheumatoid Arthritis Patients Who Have Had an Inadequate Response to Nonbiologic DMARDs: Systematic Literature Review and Network Meta-Analysis. Int. J. Rheumatol. 2017, 2017. [CrossRef]

164. Straub, R.H.; Tellenbach, C.; Herzog, L.; Scherer, A.; Moeller, B.; Ciurea, A.; Von Muehlenen, I.; Gabay, C.; Kyburz, D.; Brulhart, L.; et al. Comparative effectiveness of antitumour necrosis factor agents, biologics with an alternative mode of action and tofacitinib in an observational cohort of patients with rheumatoid arthritis in Switzerland. RMD Open 2020, 6, e001174. [CrossRef]

165. Reed, G.W.; Gerber, R.A.; Shan, Y.; Takiya, L.; Dandreo, K.J.; Gruben, D.; Kremer, J.; Wallenstein, G. Real-World Comparative Effectiveness of Tofacitinib and Tumor Necrosis Factor Inhibitors as Monotherapy and Combination Therapy for Treatment of Rheumatoid Arthritis. Rheumatol. Ther. 2019, 6, 573-586. [CrossRef]

166. Fleischmann, R.; Kremer, J.; Tanaka, Y.; Gruben, D.; Kanik, K.; Koncz, T.; Krishnaswami, S.; Wallenstein, G.; Wilkinson, B.; Zwillich, S.H.; et al. Efficacy and safety of tofacitinib in patients with active rheumatoid arthritis: Review of key Phase 2 studies. Int. J. Rheum. Dis. 2016, 19, 1216-1225. [CrossRef]

167. Sands, B.; Taub, P.R.; Armuzzi, A.; Friedman, G.S.; Moscariello, M.; Lawendy, N.; Pedersen, R.D.; Chan, G.; Nduaka, C.I.; Quirk, D.; et al. Tofacitinib Treatment Is Associated With Modest and Reversible Increases in Serum Lipids in Patients With Ulcerative Colitis. Clin. Gastroenterol. Hepatol. 2020, 18, 123-132.e3. [CrossRef]

168. Salgado, E.; Gomez-Reino, J.J. The JAK inhibitor tofacitinib for active rheumatoid arthritis: Results from Phase III trials. Int. J. Clin. Rheumatol. 2013, 8, 315-326. [CrossRef]

169. Schulze-Koops, H.; Strand, V.; Nduaka, C.; Demasi, R.; Wallenstein, G.; Kwok, K.; Wang, L. Analysis of haematological changes in tofacitinib-treated patients with rheumatoid arthritis across phase 3 and long-term extension studies. Rheumatology 2016, 56, 46-57. [CrossRef] [PubMed]

170. Cohen, S.; Radominski, S.C.; Gómez-Reino, J.J.; Wang, L.; Krishnaswami, S.; Wood, S.P.; Soma, K.; Nduaka, C.I.; Kwok, K.; Valdez, H.; et al. Analysis of Infections and All-Cause Mortality in Phase II, Phase III, and Long-Term Extension Studies of Tofacitinib in Patients With Rheumatoid Arthritis. Arthritis Rheumatol. 2014, 66, 2924-2937. [CrossRef] [PubMed]

171. Cohen, S.B.; Tanaka, Y.; Mariette, X.; Curtis, J.R.; Lee, E.B.; Nash, P.; Winthrop, K.L.; Charles-Schoeman, C.; Thirunavukkarasu, K.; Demasi, R.; et al. Long-term safety of tofacitinib for the treatment of rheumatoid arthritis up to 8.5 years: Integrated analysis of data from the global clinical trials. Ann. Rheum. Dis. 2017, 76, 1253-1262. [CrossRef]

172. Curtis, J.R.; Lee, E.B.; Kaplan, I.V.; Kwok, K.; Geier, J.; Benda, B.; Soma, K.; Wang, L.; Riese, R. Tofacitinib, an oral Janus kinase inhibitor: Analysis of malignancies across the rheumatoid arthritis clinical development programme. Ann. Rheum. Dis. 2015, 75, 831-841. [CrossRef]

173. European Medicines Agency. Restrictions in Use of Xeljanz While EMA Reviews Risk of Blood Clots in Lungs; EMA: Amsterdam, The Netherlands, 2019.

174. Lee, M.-Y.; Park, S.-K.; Park, S.-Y.; Byun, J.-H.; Lee, S.-M.; Ko, S.-K.; Lee, E.-K. Cost-effectiveness of Tofacitinib in the Treatment of Moderate to Severe Rheumatoid Arthritis in South Korea. Clin. Ther. 2015, 37, 1662-1676.e2. [CrossRef]

175. Bellinvia, S.; Edwards, C.J. JAK Inhibitors in the Treatment Algorithm of Rheumatoid Arthritis: A Review. EMJ Rheumatol. 2018, 5, 59-65.

176. Kulikov, A.Y.; Komarov, I.; Zinchuk, I. Pharmacoeconomic Analysis Tofacitinib Use in Rheumatoid Arthritis Treatment Scheme. Value Health 2014, 17, A381. [CrossRef] 
177. Claxton, L.; Taylor, M.; Soonasra, A.; Bourret, J.A.; Gerber, R.A. An Economic Evaluation of Tofacitinib Treatment in Rheumatoid Arthritis After Methotrexate or After 1 or 2 TNF Inhibitors from a U.S. Payer Perspective. J. Manag. Care Spéc. Pharm. 2018, 24, 1010-1017. [CrossRef]

178. Claxton, L.; Jenks, M.; Wallenstein, G.; Moynagh, D.; Taylor, M.; Mendelsohn, A.M.; Bourret, J.A.; Singh, A.; Gerber, R.A. An Economic Evaluation of Tofacitinib Treatment in Rheumatoid Arthritis: Modeling the Cost of Treatment Strategies in the United States. J. Manag. Care Spéc. Pharm. 2016, 22, 1088-1102. [CrossRef]

179. Uttley, L.; Bermejo, I.; Ren, S.; James, M.M.; Wong, R.; Scott, D.L.; Young, A.; Stevenson, M. Tofacitinib for Treating Rheumatoid Arthritis After the Failure of Disease-Modifying Anti-rheumatic Drugs: An Evidence Review Group Perspective of a NICE Single Technology Appraisal. PharmacoEconomics 2018, 36, 1063-1072. [CrossRef] [PubMed]

180. Navarro, F.; Martinez-Sesmero, J.M.; Balsa, A.; Peral, C.; Montoro, M.; Valderrama, M.; Gómez, S.; De Andrés-Nogales, F.; Casado, M.A.; Oyagüez, I. Cost-effectiveness analysis of treatment sequences containing tofacitinib for the treatment of rheumatoid arthritis in Spain. Clin. Rheumatol. 2020, 1-12. [CrossRef]

181. Parmentier, J.M.; Voss, J.; Graff, C.; Schwartz, A.; Argiriadi, M.; Friedman, M.; Camp, H.S.; Padley, R.J.; George, J.S.; Hyland, D.; et al. In vitro and in vivo characterization of the JAK1 selectivity of upadacitinib (ABT-494). BMC Rheumatol. 2018, 2, 23. [CrossRef] [PubMed]

182. AbbVie Receives FDA Approval of RINVOQ ${ }^{\mathrm{TM}}$ (upadacitinib), an Oral JAK Inhibitor for the Treatment of Moderate to Severe Rheumatoid Arthritis. 2019. Available online: https://news.abbvie.com/news/press-releases/abbvie-receives-fda-approval-rinvoq-upadacitinib-anoral-jak-inhibitor-for-treatment-moderate-to-severe-rheumatoid-arthritis.htm (accessed on 16 August 2019).

183. Genovese, M.C.; Smolen, J.S.; Weinblatt, M.E.; Burmester, G.R.; Meerwein, S.; Camp, H.S.; Wang, L.; Othman, A.A.; Khan, N.; Pangan, A.L.; et al. Efficacy and Safety of ABT-494, a Selective JAK-1 Inhibitor, in a Phase IIb Study in Patients With Rheumatoid Arthritis and an Inadequate Response to Methotrexate. Arthritis Rheumatol. 2016, 68, 2857-2866. [CrossRef]

184. Kameda, H.; Takeuchi, T.; Yamaoka, K.; Oribe, M.; Kawano, M.; Zhou, Y.; Othman, A.A.; Pangan, A.L.; Kitamura, S.; Meerwein, S.; et al. Efficacy and safety of upadacitinib in Japanese patients with rheumatoid arthritis (SELECT-SUNRISE): A placebo-controlled phase IIb/III study. Rheumatology 2020, keaa084. [CrossRef]

185. Burmester, G.R.; Kremer, J.M.; Bosch, F.V.D.; Kivitz, A.; Bessette, L.; Li, Y.; Zhou, Y.; Othman, A.A.; Pangan, A.L.; Camp, H.S. Safety and efficacy of upadacitinib in patients with rheumatoid arthritis and inadequate response to conventional synthetic disease-modifying anti-rheumatic drugs (SELECT-NEXT): A randomised, double-blind, placebo-controlled phase 3 trial. Lancet 2018, 391, 2503-2512. [CrossRef]

186. Genovese, M.C.; Fleischmann, R.; Combe, B.; Hall, S.; Rubbert-Roth, A.; Zhang, Y.; Zhou, Y.; Mohamed, M.-E.F.; Meerwein, S.; Pangan, A.L. Safety and efficacy of upadacitinib in patients with active rheumatoid arthritis refractory to biologic disease-modifying anti-rheumatic drugs (SELECT-BEYOND): A double-blind, randomised controlled phase 3 trial. Lancet 2018, 391, 2513-2524. [CrossRef]

187. Smolen, J.S.; Pangan, A.L.; Emery, P.; Rigby, W.; Tanaka, Y.; Vargas, J.I.; Zhang, Y.; Damjanov, N.; Friedman, A.; Othman, A.A.; et al. Upadacitinib as monotherapy in patients with active rheumatoid arthritis and inadequate response to methotrexate (SELECT-MONOTHERAPY): A randomised, placebo-controlled, double-blind phase 3 study. Lancet 2019, 393, 2303-2311. [CrossRef]

188. Euctr, S.K. A Study to Compare Upadacitinib (ABT-494) Monotherapy to Methotrexate Monotherapy in Subjects with Rheumatoid Arthritis (RA) Who Have Not Previously Taken Methotrexate (SELECT-EARLY). 2015. Available online: http://WwwWhoInt/Trialsearch/Trial2Aspx?TrialID=EUCTR2015-003334-27-SK (accessed on 31 March 2019).

189. Fleischmann, R.; Pangan, A.L.; Mysler, E.; Bessette, L.; Peterfy, C.; Durez, P.; Ostor, A.; Li, Y.; Zhou, Y.; Othman, A.A.; et al. A phase 3, randomized, double-blind study comparing upadacitinib to placebo and to adalimumab, in patients with active rheumatoid arthritis with inadequate response to methotrexate. Arthritis Rheumatol. 2018, 70, 988-990.

190. Fleischmann, R.; Genovese, M.C.; Enejosa, J.V.; Mysler, E.; Bessette, L.; Peterfy, C.; Durez, P.; Ostor, A.; Li, Y.; Song, I.-H. Safety and effectiveness of upadacitinib or adalimumab plus methotrexate in patients with rheumatoid arthritis over 48 weeks with switch to alternate therapy in patients with insufficient response. Ann. Rheum. Dis. 2019, 78, 1454-1462. [CrossRef] [PubMed] 
191. Fleischmann, R.; Pangan, A.L.; Song, I.; Mysler, E.; Bessette, L.; Peterfy, C.; Durez, P.; Ostor, A.J.; Li, Y.; Zhou, Y.; et al. Upadacitinib Versus Placebo or Adalimumab in Patients With Rheumatoid Arthritis and an Inadequate Response to Methotrexate: Results of a Phase III, Double-Blind, Randomized Controlled Trial. Arthritis Rheumatol. 2019, 71, 1788-1800. [CrossRef] [PubMed]

192. Mohamed, M.F.; Coppola, S.; Feng, T.; Camp, H.O.A. Lack of clinically-relevant effect of upadacitinib on plasma exposures of rosuvastatin and atorvastatin. Clin. Pharmacol. Drug Dev. 2019, 8, S1.

193. Astellas Pharma. Oral JAK Inhibitor Smyraf ${ }^{\circledR}$ Tablets Approved in Japan for the Treatment of rheUmatoid Arthritis (Including Prevention of Structural Joint Damage) in Patients Who Have an Inadequate Response to Conventional Therapies. 2019. Available online: https://www.astellas.com/en/news/14651 (accessed on 11 February 2020).

194. Markham, A.; Keam, S.J. Peficitinib: First Global Approval. Drugs 2019, 79, 887-891. [CrossRef] [PubMed]

195. Parganas, E.; Wang, D.; Stravopodis, D.J.; Topham, D.J.; Marine, J.-C.; Teglund, S.; Vanin, E.F.; Bodner, S.; Colamonici, O.R.; Van Deursen, J.M.; et al. Jak2 Is Essential for Signaling through a Variety of Cytokine Receptors. Cell 1998, 93, 385-395. [CrossRef]

196. Miyatake, D.; Shibata, T.; Shibata, M.; Kaneko, Y.; Oda, K.; Nishimura, T.; Katashima, M.; Sekino, H.; Furihata, K.; Urae, A. Pharmacokinetics and Safety of a Single Oral Dose of Peficitinib (ASP015K) in Japanese Subjects with Normal and Impaired Renal Function. Clin. Drug Investig. 2019, 40, 149-159. [CrossRef]

197. Cao, Y.J.; Sawamoto, T.; Valluri, U.; Cho, K.; Lewand, M.; Swan, S.; Lasseter, K.; Matson, M.; Holman, J.; Keirns, J.; et al. Pharmacokinetics, Pharmacodynamics, and Safety of ASP015K (Peficitinib), a New Janus Kinase Inhibitor, in Healthy Subjects. Clin. Pharmacol. Drug Dev. 2016, 5, 435-449. [CrossRef]

198. Takeuchi, T.; Tanaka, Y.; Iwasaki, M.; Ishikura, H.; Saeki, S.; Kaneko, Y. Efficacy and safety of the oral Janus kinase inhibitor peficitinib (ASP015K) monotherapy in patients with moderate to severe rheumatoid arthritis in Japan: A 12-week, randomised, double-blind, placebo-controlled phase IIb study. Ann. Rheum. Dis. 2015, 75, 1057-1064. [CrossRef]

199. Genovese, M.C.; Greenwald, M.; Codding, C.; Zubrzycka-Sienkiewicz, A.; Kivitz, A.J.; Wang, A.; Shay, K.; Wang, X.; Garg, J.P.; Cardiel, M.H. Peficitinib, a JAK Inhibitor, in Combination With Limited Conventional Synthetic Disease-Modifying Antirheumatic Drugs in the Treatment of Moderate-to-Severe Rheumatoid Arthritis. Arthritis Rheumatol. 2017, 69, 932-942. [CrossRef]

200. Kivitz, A.J.; Gutierrez-Ureña, S.R.; Poiley, J.; Genovese, M.C.; Kristy, R.; Shay, K.; Wang, X.; Garg, J.P.; Zubrzycka-Sienkiewicz, A. Peficitinib, a JAK Inhibitor, in the Treatment of Moderate-to-Severe Rheumatoid Arthritis in Patients With an Inadequate Response to Methotrexate. Arthritis Rheumatol. 2017, 69, 709-719. [CrossRef]

201. Tanaka, Y.; Takeuchi, T.; Tanaka, S.; Kawakami, A.; Iwasaki, M.; Song, Y.W.; Chen, Y.-H.; Wei, J.C.-C.; Lee, S.-H.; Rokuda, M.; et al. Efficacy and safety of peficitinib (ASP015K) in patients with rheumatoid arthritis and an inadequate response to conventional DMARDs: A randomised, double-blind, placebo-controlled phase III trial (RAJ3). Ann. Rheum. Dis. 2019, 78, 1320-1332. [CrossRef]

202. Takeuchi, T.; Tanaka, Y.; Tanaka, S.; Kawakami, A.; Iwasaki, M.; Katayama, K.; Rokuda, M.; Izutsu, H.; Ushijima, S.; Kaneko, Y.; et al. Efficacy and safety of peficitinib (ASP015K) in patients with rheumatoid arthritis and an inadequate response to methotrexate: Results of a phase III randomised, double-blind, placebo-controlled trial (RAJ4) in Japan. Ann. Rheum. Dis. 2019, 78, 1305-1319. [CrossRef] [PubMed]

203. Menet, C.J.; Fletcher, S.R.; Van Lommen, G.; Geney, R.; Blanc, J.; Smits, K.; Jouannigot, N.; Deprez, P.; Van Der Aar, E.M.; Clement-Lacroix, P.; et al. Triazolopyridines as Selective JAK1 Inhibitors: From Hit Identification to GLPG0634. J. Med. Chem. 2014, 57, 9323-9342. [CrossRef]

204. Namour, F.; Diderichsen, P.M.; Cox, E.; Vayssière, B.; Van Der Aa, A.; Tasset, C.; Klooster, G.V. Pharmacokinetics and Pharmacokinetic/Pharmacodynamic Modeling of Filgotinib (GLPG0634), a Selective JAK1 Inhibitor, in Support of Phase IIB Dose Selection. Clin. Pharmacokinet. 2015, 54, 859-874. [CrossRef]

205. Vanhoutte, F.; Mazur, M.; Voloshyn, O.; Stanislavchuk, M.; Van Der Aa, A.; Namour, F.; Galien, R.; Meuleners, L.; van't Klooster, G. Efficacy, Safety, Pharmacokinetics, and Pharmacodynamics of Filgotinib, a Selective JAK-1 Inhibitor, After Short-Term Treatment of Rheumatoid Arthritis: Results of Two Randomized Phase IIa Trials. Arthritis Rheumatol. 2017, 69, 1949-1959. [CrossRef] 
206. Kavanaugh, A.; Kremer, J.; Ponce, L.; Cseuz, R.; Reshetko, O.V.; Stanislavchuk, M.; Greenwald, M.; Van Der Aa, A.; Vanhoutte, F.; Tasset, C.; et al. Filgotinib (GLPG0634/GS-6034), an oral selective JAK1 inhibitor, is effective as monotherapy in patients with active rheumatoid arthritis: Results from a randomised, dose-finding study (DARWIN 2). Ann. Rheum. Dis. 2016, 76, 1009-1019. [CrossRef] [PubMed]

207. Westhovens, R.; Taylor, P.C.; Alten, R.; Pavlova, D.; Enríquez-Sosa, F.; Mazur, M.; Greenwald, M.; Van Der Aa, A.; Vanhoutte, F.; Tasset, C.; et al. Filgotinib (GLPG0634/GS-6034), an oral JAK1 selective inhibitor, is effective in combination with methotrexate (MTX) in patients with active rheumatoid arthritis and insufficient response to MTX: Results from a randomised, dose-finding study (DARWIN 1). Ann. Rheum. Dis. 2016, 76, 998-1008. [CrossRef] [PubMed]

208. Genovese, M.C.; Kalunian, K.; Gottenberg, J.-E.; Mozaffarian, N.; Bartok, B.; Matzkies, F.; Gao, J.; Guo, Y.; Tasset, C.; Sundy, J.S.; et al. Effect of Filgotinib vs Placebo on Clinical Response in Patients With Moderate to Severe Rheumatoid Arthritis Refractory to Disease-Modifying Antirheumatic Drug Therapy. JAMA Am. Med. Assoc. 2019, 322, 315-325. [CrossRef]

209. Elwood, F.; Witter, D.J.; Piesvaux, J.; Kraybill, B.; Bays, N.; Alpert, C.; Goldenblatt, P.; Qu, Y.; Ivanovska, I.; Lee, H.-H.; et al. Evaluation of JAK3 Biology in Autoimmune Disease Using a Highly Selective, Irreversible JAK3 Inhibitor. J. Pharmacol. Exp. Ther. 2017, 361, 229-244. [CrossRef]

210. Farmer, L.J.; Ledeboer, M.W.; Hoock, T.; Arnost, M.J.; Bethiel, R.S.; Bennani, Y.L.; Black, J.J.; Brummel, C.L.; Chakilam, A.; Dorsch, W.A.; et al. Discovery of VX-509 (Decernotinib): A Potent and Selective Janus Kinase 3 Inhibitor for the Treatment of Autoimmune Diseases. J. Med. Chem. 2015, 58, 7195-7216. [CrossRef]

211. Fleischmann, R.; Damjanov, N.S.; Kivitz, A.J.; Legedza, A.; Hoock, T.; Kinnman, N. A Randomized, Double-Blind, Placebo-Controlled, Twelve-Week, Dose-Ranging Study of Decernotinib, an Oral Selective JAK-3 Inhibitor, as Monotherapy in Patients With Active Rheumatoid Arthritis. Arthritis Rheumatol. 2015, 67, 334-343. [CrossRef]

212. Genovese, M.C.; Van Vollenhoven, R.F.; Pacheco-Tena, C.; Zhang, Y.; Kinnman, N. VX-509 (Decernotinib), an Oral Selective JAK-3 Inhibitor, in Combination With Methotrexate in Patients With Rheumatoid Arthritis. Arthritis Rheumatol. 2015, 68, 46-55. [CrossRef] [PubMed]

213. Genovese, M.C.; Yang, F.; Østergaard, M.; Kinnman, N. Efficacy of VX-509 (decernotinib) in combination with a disease-modifying antirheumatic drug in patients with rheumatoid arthritis: Clinical and MRI findings. Ann. Rheum. Dis. 2016, 75, 1979-1983. [CrossRef] [PubMed]

214. European Medicines Agency. Public Summary of Opinion on Orphan Designation Itacitinib for Treatment of Graft-Versus-Host Disease; EMA: London, UK, 2018.

215. Genovese, M.C.; Jarosova, K.; Cieślak, D.; Alper, J.; Kivitz, A.; Hough, D.; Maes, P.; Pineda, L.; Chen, M.; Zaidi, F. Apremilast in patients with active rheumatoid arthritis: A phase II, multicenter, randomized, double-blind, placebo-controlled, parallel-group study. Arthritis Rheumatol. 2015, 67, 1703-1710. [CrossRef] [PubMed]

216. Srinivas, N.; Barbour, A.M.; Epstein, N.; Zhou, G.; Petusky, S.; Xun, Z.; Yuska, B.; Marbury, T.; Chen, X.; Yeleswaram, S.; et al. The Effect of Renal Impairment on the Pharmacokinetics and Safety of Itacitinib. J. Clin. Pharmacol. 2020. [CrossRef]

217. Gong, X.; Darpo, B.; Xue, H.; Punwani, N.; He, K.; Barbour, A.M.; Epstein, N.; Landman, R.; Chen, X.; Yeleswaram, S. Evaluation of Clinical Cardiac Safety of Itacitinib, a JAK1 Inhibitor, in Healthy Participants. Clin. Pharmacol. Drug Dev. 2019. [CrossRef]

218. Mok, C.C. The Jakinibs in systemic lupus erythematosus: Progress and prospects. Expert Opin. Investig. Drugs 2018, 28, 85-92. [CrossRef]

219. Dodington, D.; Desai, H.R.; Woo, M. JAK/STAT_Emerging Players in Metabolism. Trends Endocrinol. Metab. 2018, 29, 55-65. [CrossRef]

(C) 2020 by the authors. Licensee MDPI, Basel, Switzerland. This article is an open access article distributed under the terms and conditions of the Creative Commons Attribution (CC BY) license (http://creativecommons.org/licenses/by/4.0/). 